\title{
La construcción social de la pobreza y la desvalorización de los pobres en México en quince años del diario El Universal
}

\section{The social construction of poverty and the devaluation of the poor in Mexico in fifteen years of the newspaper El Universal}

\author{
DOI: https:/doi.org// 0.32870/ \\ eees.v26i76.7080
}

\section{Resumen}

Este artículo se inscribe en una perspectiva sociológica constructivista, y enfatiza las dimensiones simbólicas de la pobreza y el ejercicio de la violencia simbólica contra los pobres, por lo que busca ayudar a revelar los mecanismos sociales que contribuyen a estigmatizar y desvalorizar a dicha población. Para ello, analiza publicaciones realizadas entre 2000 y 2014 a propósito de la pobreza en el diario El Universal (México). Se aplica el análisis crítico del discurso a un corpus de trescientos setenta y nueve artículos, que permite detectar un énfasis en la perspectiva gubernamental, aunque ocasionalmente se incluyen algunas visiones críticas; que el tema de la pobreza se circunscribe al ámbito rural -campesinos e indígenas, con poca agencia, salvo criminal-, y con poca presencia de la pobreza urbana;y que se estigmatiza y caracteriza a los pobres como amenazas para la seguridad pública y la sociedad.

Palabras clave: pobreza, violencia simbólica, construcción social, El Universal,

México.

\author{
Carlos Barba Solano \\ Enrique Valencia Lomelí»
}

\begin{abstract}
This article is inscribed in a constructivist sociological perspective, and emphasizes the symbolic dimensions of poverty and the exercise of symbolic violence against the poor, so it seeks to reveal the social mechanisms that contribute to stigmatizing and devaluing that population. To do this, it analyzes publications made between 2000 and 2014 regarding poverty in El Universal newspaper (Mexico). Critical discourse analysis is applied to a corpus of three hundred and seventy-nine articles, which allows to detect an emphasis on the governmental perspective, although occasionally some critical views are included; that the issue of poverty is limited to rural areas -farmers and indigenous, with little agency, except criminal, and with little presence of urban poverty; and that the poor are stigmatized and characterized as threats to public safety and society.
\end{abstract}

Keywords: Poverty, simbolic violence, social construction, El Universal, Mexico.

\footnotetext{
- Profesor-Investigador del Departamento de Estudios Sociourbanos de la Universidad de Guadalajara, México. ORCID: https://orcid.org/0000-000I-5886-8564

carlosbarba66@gmail.com

- Profesor-Investigador del Centro Universitario de Ciencias Sociales y Humanidades (CUCSH)

de la Universidad de Guadalajara, México. ORCID: https://orcid.org/0000-000 I-6895-5928

enrivalo@gmail.com

Fecha de recepción: 09 de enero de 2019. Fecha de aceptación: 04 de julio de 2019.
} 
Introducción'

En México, durante los últimos treinta años, en términos discursivos la pobreza se ha convertido en el aspecto central de la cuestión social. Esto ha obedecido no únicamente a su enorme peso demográfico, ${ }^{2}$ sino a los dilemas morales y la carga de ilegitimidad política que su mera existencia, y aún más su persistencia, plantea a la sociedad y al Estado mexicanos, incluso según los cálculos oficiales (Valencia, Foust, y Tetreault, 2012a).

La situación en torno a la pobreza fue distinta durante el periodo conocido como industrialización vía la sustitución de las importaciones (ISI). En esa etapa, la política social mexicana, ligada estrechamente con los procesos de crecimiento económico, buscaba contribuir a la incorporación del mayor número posible de trabajadores asalariados a las instituciones de seguridad social (con su creación, a partir de 1943), y se proponía acompañar ese proceso con incrementos a los salarios reales. ${ }^{3}$

Sin embargo, durante los años setenta, los límites económicos y sociales de este modelo empezaron a manifestarse. Se ralentizó la incorporación de los trabajadores a la seguridad social, y la problemática de la pobreza, sobre todo en el ámbito rural, fue reconocida e incorporada a la agenda de las políticas públicas federales (Ordoñez, 2002; Barba, 2003). A partir de ese momento, la conceptualización de la pobreza se convirtió en un tema estratégico para la legitimación del Estado, no sólo en términos de la agenda

I. Este trabajo contó con la colaboración de Andrea Moreno Quiroz, quien ayudó a depurar y analizar la base de datos del periódico El Universal, construida especialmente para esta investigación.

2. De acuerdo con Consejo Nacional de Evaluación de la Política de Desarrollo Social (2016), en México, en 2016 había 53.4 millones de pobres, es decir, el 43.6\% de la población.

3. Puede verse un balance histórico de las políticas sociales al interior del régimen de bienestar mexicano en Barba y Valencia (20I4). 
política y de las políticas públicas, sino también en términos simbólicos (Barba, 2012; Bayón, 2015a y 2015b).

En el campo académico, la discusión sobre la pobreza adquirió también un lugar muy relevante. Desde la década de 1990, muchos investigadores han analizado este fenómeno, abordado su incidencia ${ }^{4}$ y persistencia, y formulado recomendaciones y tratado de influir en el diseño, puesta en práctica y evaluación de las políticas para reducir la pobreza $^{5}$ (Valencia, Foust, y Tetreault, 2012a).

En ese contexto, se ha retomado la perspectiva relacional y constructivista sobre la pobreza, ${ }^{6}$ que fue iniciada por Georg Simmel con la publicación de su célebre ensayo $E l$ pobre, aparecido en la revista Soziologie en 1908 (Simmel, 1977). Simmel subraya que las categorías pobre y pobreza son construidas socialmente para referir a quienes son asistidos a través de programas, política e instituciones sociales. Para la perspectiva constructivista, esas dos categorías desvalorizan ciertas formas de vida e imponen externamente roles, etiquetas y significados a un conjunto de personas concebidas como una capa homogénea de asistidos,${ }^{7}$ esto a pesar de que dichas personas experimentan realidades muy heterogéneas ${ }^{8}$ (Simmel, 1977, pp. 515-518; Ivo, 2008; Paugman, 2007).

4. El número de personas por debajo de una línea de pobreza establecida. 5. En el trabajo de Valencia, Foust y Tetreault (2012a), se pueden encontrar evidencias muy claras sobre la búsqueda de la academia de incidencia práctica en las políticas sociales. El libro trabaja a partir de una muestra significativa de publicaciones científicas mexicanas producidas entre 1989 y 2009 , de la que se recuperaron ciento cincuenta y siete artículos de ciento sesenta y ocho académicos, en los que se encontraron doscientas setenta y siete recomendaciones de políticas sociales. Esto muestra que la pobreza se convirtió efectivamente en una problemática relevante -y su estudio en un campo de lucha- de las ciencias sociales en las décadas siguientes a los años noventa.

6. Destacan en este campo los trabajos realizados por Bayón (20I2, 20I3, 20I5a y 20 I5b), Bayón y Saraví (20 I3), Saraví (2008 y 20I5) y Barba (20I2).

7. Es decir, no como conceptos que expresan una experiencia $\circ$ una identidad vividas individualmente.

8. Paugman (2007), por ejemplo, en el contexto de las sociedades desarrolladas y democráticas, subraya que la pobreza no es universal y, por ello, contrasta las 
El presente artículo se inscribe en esa perspectiva sociológica y busca profundizar en los mecanismos sociales que contribuyen a estigmatizar y desvalorizar a los pobres, pero no se pretende circunscribirlo al ámbito de las ciencias sociales, sino explorar la manera en que la pobreza es analizada, presentada y juzgada en espacios donde circulan de manera masiva representaciones sociales.

Van Dijk (2010) señala que, después de la televisión, el discurso mediático más influyente en términos sociales es el de la prensa, particularmente entre las élites sociales, culturales, económicas y políticas. Por ello, se escogió para el presente trabajo el campo de la producción de noticias y editoriales periodísticos, y se revisará cómo la pobreza y los pobres son representados en un diario mexicano de circulación nacional, El Universal.

En este periódico, en años recientes se han publicado numerosas noticias y editoriales relacionados con la pobreza, cuyos propósitos y destinatarios han sido poco estudiados, pero que se enmarcan en un contexto de violencia simbólica ${ }^{9}$ contra de los pobres. El objetivo de este trabajo es analizar algunos de estos productos mediáticos, usados para denostar a los pobres,$^{10}$ aparecidos entre los años 2000 y 2014 , que han contribuido a fijar agendas políticas e interpretativas alrededor de esta temática.

Los productos analizados en este trabajo fueron escogidos a través de un muestreo representativo de un corpus extenso, construido especialmente para esta investigación, integrado por 23764 artículos que abordan el tema de la

\footnotetext{
diferencias que existen entre la pobreza de los barrios conflictivos de las ciudades europeas, la pobreza de las zonas rurales, la pobreza de los años setenta y la pobreza actual. Propone una tipología que contrasta tres distintas formas de pobreza: la integrada, la marginal y la descalificadora.

9.El término se define más adelante.

10. Esto no significa que no se hayan publicado artículos que escapan a esta tendencia, pero el interés es circunscribirnos a los que estigmatizan a los pobres porque constituyen la tendencia dominante en ese diario.
}

\section{6}


pobreza durante el periodo analizado. De ese conjunto, se extrajo una muestra de trescientos setenta y nueve artículos a través de un trabajo exhaustivo de revisión de la base de datos sobre el periódico en cuestión.

Los objetivos de este trabajo son dos: 1) identificar los discursos que abordan la pobreza, subrayando aquellos que asumen una visión estigmatizante en el diario ya mencionado, y también enfatizando aquellos que fijan agendas políticas o sociales alrededor de este tema (Lukes, 1976); ${ }^{11}$ y 2) examinar cómo distintas perspectivas e intereses se articulan alrededor de la construcción discursiva de la pobreza. En este sentido, el trabajo se basa en la perspectiva de Pierre Bourdieu (2001) y considera que en el campo periodístico ${ }^{12}$ se produce una batalla simbólica, mediada por agentes profesionales,$^{13}$ cuyo eje en este caso es la definición de la pobreza (Bourdieu, 2001, p. 129).

Se parte de los siguientes supuestos: las noticias, entrevistas y editoriales periodísticas sobre la pobreza, aunque suelen apelar a preocupaciones éticas de carácter universal, expresan ideologías e intereses sociales hegemónicos. ${ }^{14}$ Con frecuencia, reducen la pobreza a una escala individual o reconocen a los pobres como una categoría social abstracta, utilizada para desvalorizar a distintos conjuntos de perso-

I I.Steve Lukes ( 1976, p. 2 I) señala que el enfoque bidimensional del poder subraya tanto la centralidad del control sobre la agenda de las políticas públicas como las formas utilizadas para dejar por fuera del proceso político asuntos potenciales que podrían ser abordados por dichas políticas.

12. El concepto de campo se refiere a un conjunto de relaciones objetivas e históricas de poder, donde prevalece el conflicto y la competencia, tanto a escala individual como colectiva. Bourdieu (200I, Pp. 14-15) considera a los campos como espacios de lucha donde agentes dotados de distintas cantidades de recursos compiten entre sí por acumular los bienes que están disponibles en un ámbito particular. Las características de los discursos que se generan en el campo periodístico serán presentadas más adelante.

13. Es decir, profesionales de la producción de representaciones sociales en los medios de comunicación, a través de editoriales, reportajes y noticias.

14. El concepto de hegemonía fue desarrollado por Antonio Gramsci ( I98I) para referirse a la dirección intelectual y moral ejercida por un grupo o por una coalición social sobre otros grupos (aliados o subordinados).

Sociedad No.76 
nas. En estos productos periodísticos, la pobreza es representada como un problema social que debe resolverse, pero no se distingue la heterogeneidad de los grupos que suelen categorizarse como pobres (Paugman, 2007).

De igual forma, se asume que las prácticas discursivas inscritas en esta clase de productos mediáticos inciden en la construcción social de la pobreza; en las maneras como los pobres son visibilizados, objetivados u ocultados; en el estatus social que se les atribuye; en la naturalización de la que son objeto; o en su presentación como evidencia de alguna anomalía socioeconómica o sociocultural.

El artículo se divide en cinco secciones. La primera es de carácter teórico, y explora la relación entre violencia simbólica y pobreza; la segunda presenta la estrategia metodológica; la tercera explora la relación que existe entre el discurso periodístico y la cuestión social; la cuarta realiza un análisis general de la muestra ya mencionada; y la quinta presenta un análisis a profundidad de tres casos representativos de notas. Finalmente, se señalan las conclusiones.

Cabe señalar que el análisis a profundidad se concentró en tres géneros periodísticos en que se produce una interacción muy clara entre el discurso periodístico y el gubernamental: una colaboración realizada por un exfuncionario público, ${ }^{15}$ considerado colaborador experto; un reportaje crítico realizado por dos periodistas del diario, que presenta los puntos de vista de algunos beneficiarios de un programa social; ${ }^{16}$ y una entrevista realizada a una funcionaria pública en funciones ${ }^{17}$ en relación con la construcción de un nuevo programa social.

I5.La intención es mostrar no sólo la mirada de un exfuncionario, el expresidente de México Ernesto Zedillo, sino la manera en que su colaboración es presentada como la perspectiva de un experto.

16. La idea es ejemplificar cómo son recogidas las voces de los beneficiarios de programas sociales en el periódico analizado.

17. Se trata de Rosario Robles, quien en 2013 era secretaria de Desarrollo Social en el Gobierno de Enrique Peña Nieto. 
Por cuestiones de espacio, se decidió no incluir explícitamente los discursos de organizaciones internacionales porque estos han sido abordados con mayor amplitud en otros trabajos (Barba, 2007b; Barba y Silva, 2018), ${ }^{18}$ ni los discursos de colaboradores académicos porque ocupan un espacio bastante menor en el corpus analizado. Sin embargo, en la tercer nota señalada (entrevista), se interpela no sólo al Gobierno federal, sino a instituciones financieras internacionales (como el Banco Interamericano de Desarrollo-BIDy el Banco Mundial-BM-) y a académicos de la Universidad Nacional Autónoma de México (UNAM) que participan en la evaluación y en la reingeniería del programa social.

\section{La violencia simbólica y la pobreza}

En el campo del poder, como señalaba Bourdieu (1997), la objetividad del mundo social se refiere no sólo a la distribución y apropiación de recursos materiales, sino a sistemas de clasificación simbólica. Estos son sistemas arbitrarios, frecuentemente bipolares (Tilly, 2000), ${ }^{19}$ enraizados en la oposición fundamental entre dominantes y dominados, que expresan jerarquías sociales y son matrices de actividades prácticas, pensamientos, sentimientos y juicios realizados por actores sociales, a través de los cuales se produce y reproducen las desigualdades sociales. Dichos sistemas implican una conexión entre las estructuras sociales y cognitivas, y por ello permiten que las distinciones sociales puedan internalizarse (Bourdieu, 1997).

18. Aunque el discurso académico suele ser más crítico que el periodístico, no fue abordado aquí porque su presencia en el corpus analizado es marginal y había más interés en mostrar casos más emblemáticos en dicho corpus.

19. Tilly (2000) sostiene que la desigualdad es producto de la existencia de mecanismos de explotación, de la construcción simbólica de sistemas bipolares de categorías desiguales, de la exclusión, del acaparamiento de oportunidades y de procesos de estigmatización, que reproducen matrices de relaciones sociales desiguales de muchos tipos: étnicas, de estatus, de clase, de género, etc. 
Siguiendo esta perspectiva, Bayón afirma la necesidad de considerar, además de las bases materiales de la pobreza, las dimensiones simbólicas ${ }^{20}$ y relacionales que contribuyen a producirla, mantenerla y reproducirla (Bayón, 2015a, p. 357). Recordando a Simmel (1977), esta autora señala que la pobreza refiere no sólo a la privación o carencia de satisfactores básicos experimentada a nivel individual, familiar o grupal, sino a la construcción de los pobres como una categoría social que tiende a naturalizar las desigualdades sociales a través de distintos discursos sociales.

Desde este punto de vista teórico, las percepciones sobre la pobreza pueden servir para legitimarla y ser elementos fundamentales en el ejercicio de la violencia simbólica que, como señala Bourdieu (1997), arranca sumisiones que ni siquiera se perciben como tales, que se apoyan en expectativas colectivas y en creencias socialmente inculcadas que permiten transformar relaciones de dominación en relaciones afectivas. ${ }^{21}$ Se trata de una violencia que logra que los dominados acepten como legítima su propia condición de dominación (Bourdieu, 1997, pp. 172-173; Bourdieu y Wacquant, 2005, p. 240).

En el caso que se analiza, esta violencia se refiere a mecanismos y prácticas simbólicas que contribuyen a lograr que quienes son catalogados como pobres lleguen a considerar natural su condición de inferioridad, e inciden en su exclusión en distintos ámbitos sociales.

20. Para Bourdieu, lo simbólico es material, pero no se reconoce como tal (el gusto en el vestir, las preferencias musicales, las formas de hablar, el estilo), y de ahí deriva su eficacia estructural.

21 . Un ejemplo de ello son los regalos (dones) que no implican una relación de reciprocidad porque no pueden ser correspondidos, y por ello crean una obligación duradera que vincula a quien los recibe con quien los regala en una relación de deuda personal. 


\section{El análisis crítico del discurso y la pobreza}

Para revelar dichos mecanismos, se requiere una metodología capaz de descifrar significados construidos discursivamente y, en el caso que nos interesa aquí, inmersos en discursos periodísticos. Esta tarea puede realizarse a través del análisis del discurso, que no sólo considera lo que es denotado literalmente en un texto, sino también los elementos que lo connotan, las piezas que abren y amplían su significado, que van más allá de lo que está estrictamente contenido en él (Barthes, 1995). ${ }^{22}$

Para cumplir con los objetivos establecidos en este trabajo, una herramienta fundamental es el análisis crítico del discurso (ACD), porque fue desarrollado para dar cuenta del ejercicio simbólico del poder a través de discursos, a los que considera objetos históricos e interacciones comunicativas que acontecen en situaciones sociales emplazadas en un contexto espacio-temporal particular (Van Dijk, 2010, p. 78; Wodak, 2003, pp. 19-20). ${ }^{23}$

Como señala Wodak, el carácter crítico de esta metodología alude a una toma de distancia respecto a las prácticas discursivas para enmarcarlas socialmente, y también implica adoptar una postura política frente a ellas porque a través de ellas se ejerce el poder (o se desafía). La autora señala que dichas prácticas pueden estar basadas en ideologías, y por ello suelen adquirir sus características (racismo, sexismo, individualismo) (Van Dijk, 2010, pp. 76-79).

Wodak (2003, pp. 20, 29-30, 32, 34) advierte también que los discursos estabilizan las convenciones, las convierten en algo natural y enmascaran los efectos del poder y de las ideologías en la producción de sentido. De ahí la necesidad

22. Roland Barthes (1995, pp. 16, 25, 34) afirma que un sistema de connotación toma los signos de otro sistema para convertirlos en sus propios significantes, modificando su sentido literal y agregándole un sentido simbólico adicional que puede ser ideológico.

23.Por ello, su comprensión depende precisamente de dicho contexto.

Sociedad No.76 
de que los analistas desentrañen dichos efectos y los hagan visibles.

Para el ACD, la manera como se construye discursivamente a los otros y a nosotros forma parte de la estructura subyacente que afecta sistemáticamente a los usos del lenguaje dirigidos a reproducir distintos tipos de desigualdad. El ACD encuadra dichas construcciones en lo que Van Dijk (2010) denomina el casillero ideológico (Tabla 1).

Tabla 1. Casillero ideológico

Nosotros

Enfatizar nuestras cosas buenas

Disimular nuestras cosas malas
Los otros

Enfatizar sus cosas malas Disimular sus cosas buenas

Fuente: elaboración propia con base en Van Dijk (2010, p. 81).

Esta oposición tiene repercusiones en otras prácticas discursivas, como la construcción de identidades (quiénes somos y quiénes son ellos), la valoración de las acciones (lo que hacemos y lo que ellos hacen), las explicitación de metas (lo que buscamos y lo que ellos buscan), la enunciación de normas y valores (lo bueno y lo malo, lo permitido y lo prohibido) y la ponderación de los recursos con los que se cuenta (poder y ausencia de poder) (Van Dijk, 2010, p. 80).

Se pueden aplicar estos principios generales a las estructuras semánticas (sentido y referente) del discurso, que abordan aspectos fundamentales como los que aparecen en la Tabla 2. 


\section{Tabla 2. Estructuras semánticas}

\begin{tabular}{|c|c|c|}
\hline $\begin{array}{l}\text { Estructura } \\
\text { semántica }\end{array}$ & $\begin{array}{l}\text { Papel dentro del discurso } \\
\text { para construir a distintos } \\
\text { tipos de sujetos }\end{array}$ & $\begin{array}{l}\text { Repercusiones discursivas } \\
\text { en la construcción de "ellos" } \\
\text { y de "nosotros" }\end{array}$ \\
\hline $\begin{array}{l}\text { Temas } \\
\text { negativos }\end{array}$ & $\begin{array}{l}\text { Controlan la coherencia } \\
\text { y la interpretación de } \\
\text { todo discurso }\end{array}$ & $\begin{array}{l}\text { Presentación de ellos como } \\
\text { infractores de nuestras } \\
\text { normas y valores* }\end{array}$ \\
\hline $\begin{array}{l}\text { Nivel de } \\
\text { descripción de } \\
\text { propiedades o } \\
\text { acciones }\end{array}$ & Detallada o superficial & $\begin{array}{l}\text { Descripción detallada de } \\
\text { las propiedades y acciones } \\
\text { negativas de ellos y omisión } \\
\text { o tratamiento superficial de } \\
\text { las nuestras }\end{array}$ \\
\hline Presuposiciones & $\begin{array}{l}\text { Ideas que no se } \\
\text { comprueban o } \\
\text { argumentan }\end{array}$ & $\begin{array}{l}\text { Empleadas negativamente } \\
\text { sobre ellos }\end{array}$ \\
\hline Denominación & Subrayan diferencias & $\begin{array}{l}\text { Muestran a ellos como } \\
\text { diferentes a nosotros }\end{array}$ \\
\hline Predicación & $\begin{array}{l}\text { Atribuyen características } \\
\text { positivas o negativas }\end{array}$ & $\begin{array}{l}\text { Atribuyen características } \\
\text { negativas a ellos y positivas } \\
\text { a nosotros }\end{array}$ \\
\hline Modalidad & $\begin{array}{l}\text { Expresiones modales } \\
\text { que modifican a las } \\
\text { proposiciones: necesidad, } \\
\text { probabilidad, posibilidad }\end{array}$ & $\begin{array}{l}\text { Consideran los aspectos } \\
\text { negativos como algo } \\
\text { inherente a la naturaleza } \\
\text { de ellos y los positivos como } \\
\text { algo inherente a nuestra } \\
\text { naturaleza }\end{array}$ \\
\hline Agencia & $\begin{array}{l}\text { Subrayan } \\
\text { responsabilidades } \\
\text { activas }\end{array}$ & $\begin{array}{l}\text { Resaltan la responsabilidad } \\
\text { activa de ellos en acciones } \\
\text { negativas }\end{array}$ \\
\hline
\end{tabular}

*Alrededor de temáticas como la pobreza, la desigualdad, la desviación, las amenazas, la inseguridad, la criminalidad.

**Como pobres, extranjeros, indígenas, inmigrantes, etc.

Fuente: elaboración propia con base en Van Dijk (2010, pp. 80-83).

La importancia de este análisis radica en que las prácticas sociales están fundadas en representaciones simbólicas compartidas que inciden en la actitud hacia minorías o mayorías sociales, frecuentemente desempoderadas y des- 
valorizadas. La manera como los pobres, las mujeres, los jóvenes o los migrantes son representados por distintos grupos, instituciones y organizaciones sociales repercute, por ejemplo, en la contratación, el ascenso o el despido en el trabajo, el acceso o el rechazo en las instituciones de seguridad social, de salud, de educación, e incluso en la posibilidad o imposibilidad de opinar en un ámbito público (Van Dijk, 2010, p. 84).

En lo que aquí concierne, la reproducción de la pobreza y las desigualdades también está íntimamente ligada con discursos que reproducen ideologías que naturalizan inequidades o estigmatizan categorías sociales. El discurso es decisivo porque atribuye lugares desiguales a distintos grupos sociales, y también porque es a través del texto, el habla o las imágenes como las creencias sobre la pobreza y la desigualdad son transferidas, adquiridas y confirmadas (Van Dijk, 2010, p. 93).

\section{El discurso periodístico y la cuestión social}

A partir de la perspectiva teórico-metodológica que se ha presentado, se puede considerar a las noticias, los reportajes y los editoriales de los periódicos como vehículos simbólicos organizados a través de la aplicación de códigos profesionales y técnicos que constituyen su primer nivel connotativo, ya que ningún acontecimiento desnudo puede ser publicado en un periódico, sino que antes debe asumir una forma determinada dentro del lenguaje de ese medio (Hall, 2004, p. 231).

El discurso de la prensa escrita constituye una representación de una realidad muy compleja y en constante transformación. Determinar cuáles hechos constituyen una noticia, sobre cuáles conviene hacer reportajes o sobre cuáles hay que escribir editoriales exige una construcción de la realidad social. Estos discursos son producto de dos ope-

\section{4}


La construcción social de la pobreza y la desvalorización de los pobres en México en quince años del diario El Universal

raciones básicas: la selección de acontecimientos noticiosos y la estructuración y jerarquización de dicha información (Gutiérrez Vidrio, 2010, pp. 171-172). Estas operaciones están cruzadas por relaciones y luchas de poder y por estructuras ideológicas. ${ }^{24}$

En la Tabla 3, se muestra una clasificación de los géneros periodísticos, que es de utilidad para realizar un análisis discursivo de los productos culturales que circulan en el medio analizado.

Tabla 3. Los géneros periodisticos

Género

Noticias y reportajes

Crónica, entrevista

$y$ reportaje en

profundidad

Artículo: editoria columna, crítica
Formas del discurso Caracterización

del discurso

Predominantemente narrativo y descriptivo

Explicativo

Interpretativo

Opinión

Argumentativo

Fuente: elaboración propia a partir de Gutiérrez Vidrio (2010, pp. 173-174).

Como señala Gutiérrez Cham (2003), el discurso periodístico es polifónico, y en él la voz de los actores sociales se incorpora a través de procedimientos directos o indirectos: se puede reproducir literalmente mediante citas textuales o mediante paráfrasis, pero eso no implica transparencia u objetividad porque los discursos originales se seleccionan o fragmentan en función de los intereses de quien escribe. Unas citas se introducen como citas de autoridad, mientras que otras se trivializan (Gutiérrez Cham, 2003, pp. 17-19).

24. En coyunturas de conflicto, se produce información emergente, esto es, discursos o acontecimientos que rompen parcialmente con el orden simbólico dominante como resultado de la propia agencia de algunos periodistas, inmersos en estructuras de poder más amplias (Valencia, 1989). 
Los mensajes periodísticos también están inscritos en estructuras ideológicas y políticas; eso constituye su segundo nivel connotativo: el de las relaciones sociales insertas en el proceso comunicativo (Hall, 2004, p. 218). Las piezas discursivas que se analizan aquí, todas ellas relacionadas con el tema de la pobreza, forman parte también de una órbita discursiva mayor de carácter político y académico, denominada la cuestión social. ${ }^{25}$

En el léxico de las políticas públicas, la cuestión social se refiere al espacio simbólico donde se articulan discursos, imaginarios sociales y conceptualizaciones teóricas y técnicas que definen y justifican las acciones sociales del Estado y de actores colectivos alrededor de asuntos como la pobreza, el desempleo, la desigualdad, la exclusión social o la desafiliación (Barba, 2010).

En ese sentido, en México durante los últimos veinte años, la conceptualización de la pobreza ha tendido a encerrarse en el debate entre universalismo y focalización, que ha rebasado ampliamente el campo científico e ingresado al periodístico. ${ }^{26}$ En la órbita de la cuestión social, universalismo y focalización han sido dos posturas conceptuales fuertes y contrapuestas. ${ }^{27}$ La Tabla 4 nos muestra las características de estos dos paradigmas.

25. Esta cuestión forma parte del campo científico donde, en un contexto de relaciones de poder y de significado, distintos grupos sociales compiten por el conocimiento y el reconocimiento. En él, los agentes son portadores de habitus ligados al funcionamiento de disciplinas científicas y vinculados con su formación escolar y social, con su trayectoria, posición y jerarquía en ese campo. Esta serie de disposiciones se expresan en los discursos de los actores (Bourdieu, 2003). 26. En términos políticos y de políticas públicas, son claros los adversarios y las posturas teóricas que alimentan esta disputa conceptual. Sin embargo, no se han discutido suficientemente las implicaciones de esta discrepancia en la construcción simbólica de la pobreza y de los pobres. Este trabajo intenta precisamente contribuir a esa tarea. Para una revisión de este debate, se recomienda ver: Ocampo (2008), Molina (2006) y Barba (2013).

27. Sin embargo, hay también posturas que intentan compatibilizarlas. Ejemplo de esta tentativa son las ideas de focalización dentro del universalismo de Theda Skocpol (1995) y de universalismo básico, elaborada por Molina y sus colegas (2006). 


\section{Tabla 4. Comparación entre universalismo y focalización}

\begin{tabular}{|c|c|c|}
\hline & \multicolumn{2}{|c|}{ Paradigmas } \\
\hline & Universalismo & Focalización \\
\hline Surgimiento & $\begin{array}{l}\text { Después de la Segunda } \\
\text { Guerra Mundial }\end{array}$ & $\begin{array}{l}\text { Leyes de pobres inglesas } \\
\text { de los siglos XVI y XVII }\end{array}$ \\
\hline Apogeo & $\begin{array}{l}\text { - Dominante desde su } \\
\text { surgimiento hasta las crisis } \\
\text { económicas de los años 1970- } \\
1980 \\
\text { - Resurgimiento a partir de } \\
\text { la primera década del siglo } \\
\text { XxI }\end{array}$ & $\begin{array}{l}\text {-Dominante a partir de } \\
\text { los años ochenta hasta la } \\
\text { actualidad } \\
\text {-Sujeta a fuertes críticas } \\
\text { desde los años noventa }\end{array}$ \\
\hline $\begin{array}{l}\text { Ideas } \\
\text { centrales }\end{array}$ & $\begin{array}{l}\text { - Acceso a los servicios } \\
\text { sociales garantizado por } \\
\text { el Estado para todos los } \\
\text { ciudadanos, sin distinción } \\
\text { de clase o posición en el } \\
\text { mercado } \\
\text { - Estos servicios deben } \\
\text { responder a los principios } \\
\text { democráticos de igualdad de } \\
\text { derechos y de estatus } \\
\text { - Ofrecen los mismos } \\
\text { estándares de calidad para } \\
\text { todos y cada uno de los } \\
\text { ciudadanos } \\
\text { - Se fundan en una } \\
\text { solidaridad interclasista e } \\
\text { impuestos e instituciones } \\
\text { públicas universales }\end{array}$ & $\begin{array}{l}\text { - Límites fiscales y } \\
\text { presupuestales muy } \\
\text { rigurosos para las } \\
\text { políticas sociales } \\
\text { - La tarea fundamental } \\
\text { del Estado es ofrecer } \\
\text { beneficios básicos y } \\
\text { temporales a los más } \\
\text { pobres únicamente cuando } \\
\text { estos son incapaces de } \\
\text { satisfacer sus necesidades } \\
\text { básicas a través de su } \\
\text { propia iniciativa en el } \\
\text { mercado o con el apoyo } \\
\text { familiar } \\
\text { - Trasferencias mínimas } \\
\text { de ingresos y servicios }\end{array}$ \\
\hline $\begin{array}{l}\text { Enfoque } \\
\text { fundamental }\end{array}$ & $\begin{array}{l}\text { Derechos sociales: construir } \\
\text { un derecho democrático a } \\
\text { un nivel de vida aceptable } \\
\text { garantizado para cada } \\
\text { individuo }\end{array}$ & $\begin{array}{l}\text { Asistencialismo: apoyar } \\
\text { a los menesterosos } \\
\text { que demuestran sus } \\
\text { necesidades, pero sin } \\
\text { generar dependencias o } \\
\text { derechos sociales }\end{array}$ \\
\hline $\begin{array}{l}\text { Instrumentos } \\
\text { centrales }\end{array}$ & La seguridad social & $\begin{array}{l}\text { La prueba de medios y las } \\
\text { condicionalidades }\end{array}$ \\
\hline
\end{tabular}

Sociedad No.76 


\begin{tabular}{|c|c|c|}
\hline & \multicolumn{2}{|c|}{ Paradigmas } \\
\hline & Universalismo & Focalización \\
\hline $\begin{array}{l}\text { Relación con } \\
\text { el mercado }\end{array}$ & $\begin{array}{l}\text { Desmercantilización del } \\
\text { bienestar social }\end{array}$ & $\begin{array}{l}\text { La asistencia no debe } \\
\text { distorsionar o alterar } \\
\text { el funcionamiento del } \\
\text { mercado }\end{array}$ \\
\hline $\begin{array}{l}\text { Construcción } \\
\text { simbólica de } \\
\text { la pobreza }\end{array}$ & $\begin{array}{l}\text { Considerar la pobreza como } \\
\text { un efecto sistémico negativo } \\
\text { del funcionamiento del } \\
\text { mercado }\end{array}$ & $\begin{array}{l}\text { - Atribuir la pobreza a } \\
\text { deficiencias personales de } \\
\text { diversa índole } \\
\text { - Transferir recursos a } \\
\text { los más pobres sólo bajo } \\
\text { normas estrictas y con } \\
\text { beneficios modestos (pues } \\
\text { se juzga que cuando estos } \\
\text { son excesivos reducen la } \\
\text { motivación para trabajar) }\end{array}$ \\
\hline $\begin{array}{l}\text { Efectos } \\
\text { simbólicos } \\
\text { en la } \\
\text { construcción } \\
\text { de los pobres }\end{array}$ & $\begin{array}{l}\text { - Eliminar la pobreza } \\
\text { - Abandonar la categoría } \\
\text { pobres y tratar a todos los } \\
\text { individuos como ciudadanos } \\
\text { - Incluir en el marco de } \\
\text { los derechos sociales a los } \\
\text { sectores de la población que } \\
\text { son excluidos por cuestiones } \\
\text { culturales o económicas } \\
\text { - Garantizar a cada } \\
\text { ciudadano una dotación } \\
\text { suficiente de recursos para } \\
\text { que pueda vivir una vida } \\
\text { autónoma y digna }\end{array}$ & $\begin{array}{l}\text { - Denominar a los } \\
\text { asistidos como pobres } \\
\text { - Estigmatizarlos } \\
\text { - Inducir en ellos un } \\
\text { sentimiento de culpa } \\
\text { personal y de fracaso } \\
\text { - Criminalizarlos } \\
\text { denominándolos malos } \\
\text { pobres: criminales, } \\
\text { mendigos y vagabundos } \\
\text { - Asistir sólo a } \\
\text { quienes demuestren } \\
\text { ser verdaderamente } \\
\text { necesitados y } \\
\text { dependientes } \\
\text { - Dotar a los más pobres } \\
\text { de recursos mínimos, } \\
\text { fundamentalmente de } \\
\text { capital humano, para } \\
\text { incluirlos en el mercado }\end{array}$ \\
\hline
\end{tabular}

Fuentes: elaboración propia con base en Barba (2013), Esping-Andersen (1990), Marshall (2007), Mkandawire (2005), Simmel (1977), Skocpol (1995), Titmuss (2007).

\section{8}


Esta tabla muestra claramente que el universalismo se distingue por impulsar la edificación de sistemas unificados de protección social que buscan desmercantilizar el bienestar social, es decir, ofrecer servicios sociales concebidos como derechos que aseguran a cada ciudadano (incluidos los pobres) su sustento y protección, sin depender del mercado. ${ }^{28}$ Por su parte, la premisa fundamental de la focalización es muy distinta: hay dos canales sociales legítimos a través de los cuales las necesidades del individuo deben ser satisfechas: el mercado privado y la familia, y sólo cuando estos fallan se justifica la intervención temporal del Estado para hacer frente a sus fallas.

La Tabla 4 muestra también la tensión simbólica existente entre universalismo y focalización, que juega un papel crucial en la construcción social de la pobreza y de los pobres. En la orilla universalista, la idea central es construir un derecho democrático a un nivel de vida aceptable garantizado a todos los individuos/ciudadanos ${ }^{29}$ para dotarlos de autonomía y dignidad. El objetivo es generar una sociedad más equitativa, apelando a la solidaridad entre distintas clases sociales y rechazando enfáticamente ofrecer servicios de menor calidad a quienes son pobres. Para este paradigma, es crucial la inclusión en el marco de los derechos sociales de los sectores de la población que son excluidos por cuestiones culturales o económicas.

En el borde opuesto, la focalización hunde sus raíces en las leyes de pobres del periodo isabelino inglés (siglos XVI y XVII) y, como señala Esping-Andersen (1990), tiende a culpabilizar a los pobres de su situación y a juzgarlos

28. Este paradigma ha sido un referente obligado en la construcción de las instituciones del Estado de bienestar, y en América Latina, durante la etapa ISI, dejó su mayor impronta en países como Argentina, Chile, Uruguay y Costa Rica, y en menor medida en países como Brasil y México (Esping-Andersen y Corpi, 1993; Barba, 2007a). Para una discusión amplia de los regímenes de bienestar en América Latina, se recomienda revisar: Barba (2007a).

29. Se renuncia a utilizar la categoría pobres. 
intrínsecamente como individuos inclinados a la pereza, lo que sirve de justificación para que el Estado les ofrezca beneficios modestos para evitar reducir su motivación para trabajar. Titmuss (2007) resalta que la focalización es el instrumento más efectivo para inducir entre los beneficiarios un sentimiento de culpa personal y de fracaso. ${ }^{30}$

En este contexto, la cuestión social se muestra como una estructura ideológica relevante que subyace en los discursos periodísticos que se analizan a continuación utilizando el corpus empírico ya descrito; particularmente, se observa la manera en que los discursos construyen a los otros y a nosotros alrededor de la pobreza.

\section{Los principales tipos de discursos sobre la pobreza en El Universal}

Primero, se analizan los principales tipos de discursos presentes en el diario mexicano El Universal durante el periodo 2000-2014. Para ello, en la Tabla 5 se presentan los géneros periodísticos predominantes, los contenidos, las perspectivas, las visiones sobre la pobreza y los pobres, las temáticas abordadas y las voces principales encontrados en la muestra de trescientos setenta y nueve artículos seleccionados. 

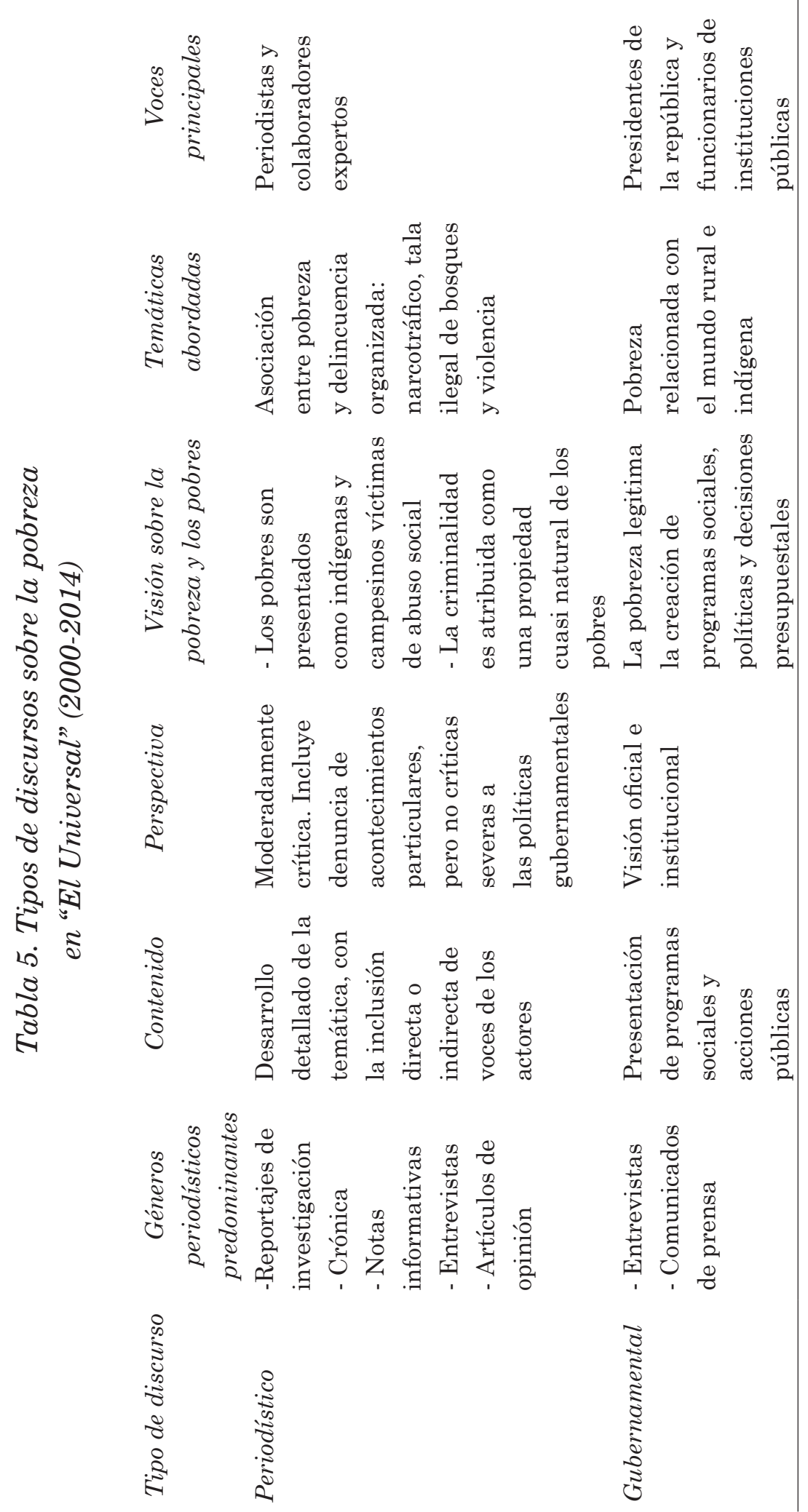

Sociedad No.76 
Carlos Barba Solano y Enrique Valencia Lomelí

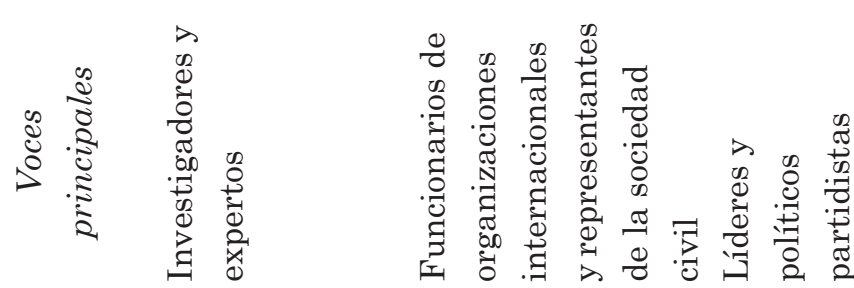

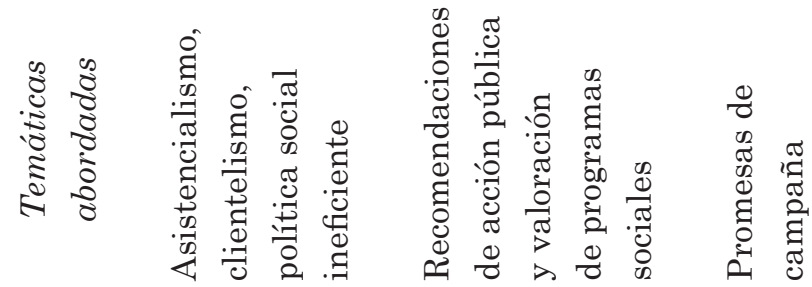

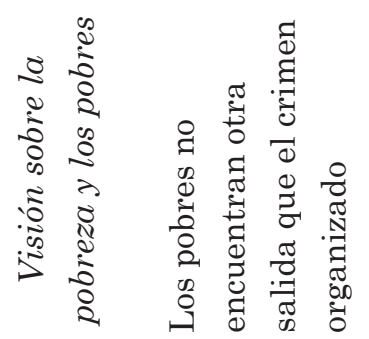

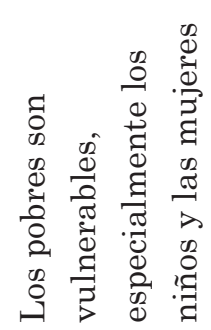
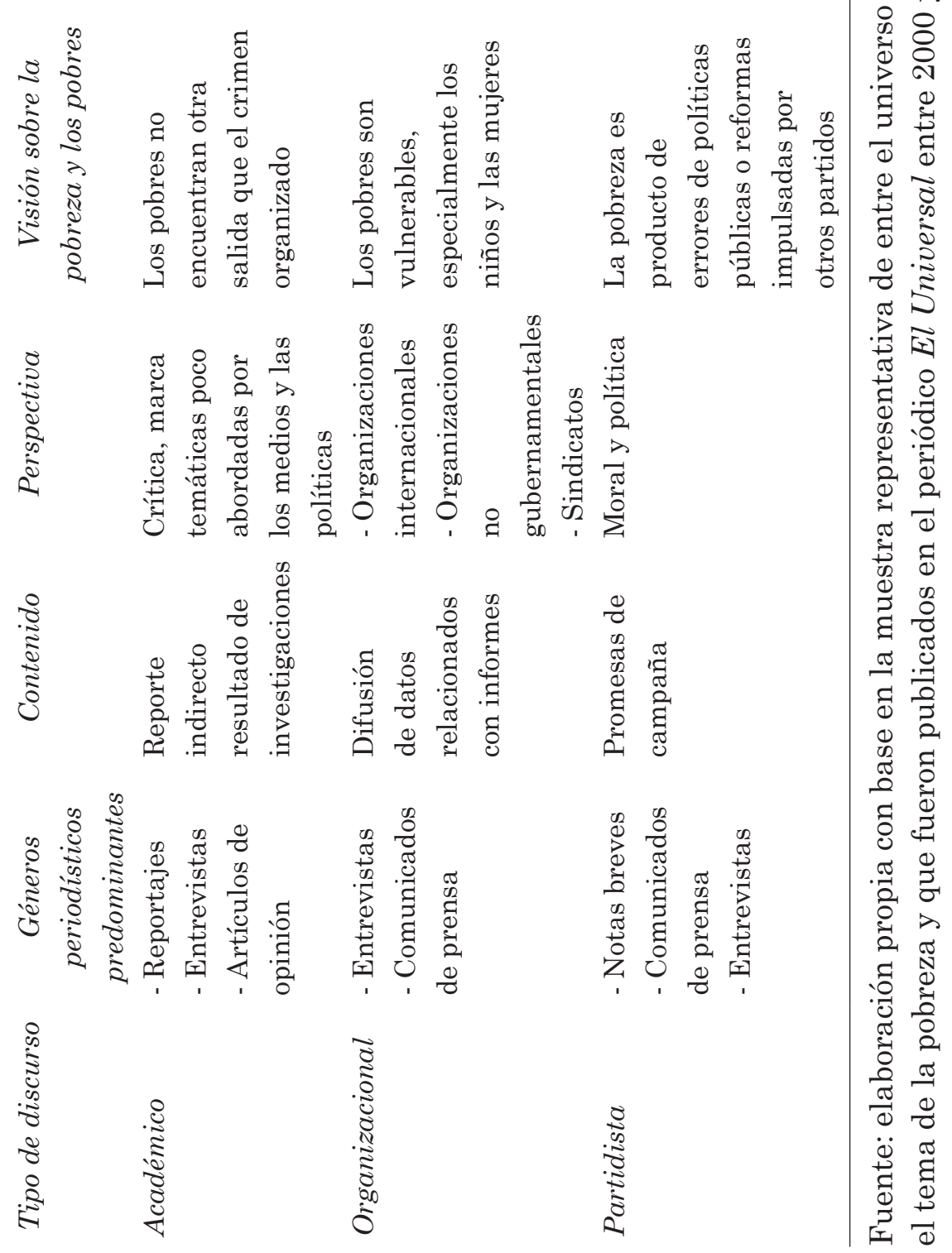
La Tabla 5 inicia presentando los principales tipos de discursos en el ámbito que aquí interesa: el periodístico, el gubernamental, el académico, el organizacional y el partidista. Entre todos ellos, sobresale el primero, que acumuló aproximadamente el $60 \%$ de las notas y reportajes dedicados a la pobreza.

El discurso periodístico, utilizado por periodistas, colaboradores y expertos, es moderadamente crítico, pero no suele relacionar los acontecimientos negativos que denuncia con errores, omisiones, negligencia o ineficacia de políticas o actores gubernamentales. En las descripciones densas ${ }^{31}$ que se realizan en este marco discursivo, aparecen de manera directa o indirecta las voces de los actores implicados en la temática. Es notable su olvido de la dimensión urbana de la pobreza y el énfasis en dos grupos sociales: los campesinos y los indígenas, quienes son vistos, a un tiempo, como víctimas de abuso social y como amenaza para la cohesión social, ya que se les vincula (sin mostrar evidencias generalizables) con la delincuencia organizada. Este discurso tiende a criminalizar a los pobres y puede ser utilizado para justificar que las políticas de seguridad pública son más adecuadas que las políticas sociales para afrontar los problemas relacionados con la pobreza.

El discurso gubernamental, utilizado por funcionarios o exfuncionarios públicos, suele ser fundamentalmente retórico $^{32}$ y se introduce en el contexto periodístico a través de entrevistas y comunicados de prensa. Acostumbra realizar propaganda política encaminada a legitimar programas sociales y decisiones en materia presupuestal. También

3I. Este concepto fue desarrollado por Clifford Geertz (2003) para referirse, desde una perspectiva antropológica, a una descripción no sólo del comportamiento social, sino también de su contexto.

32. Lausberg (1993) señala que un discurso retórico es empleado para conseguir un efecto específico. Los motivos principales son denostar, elogiar, persuadir, acusar, defender y disuadir (Sáez, 2003). 
reduce la problemática de la pobreza al mundo rural, campesino e indígena.

El discurso académico (entrevistas, artículos de opinión y reportajes), utilizado por investigadores y expertos, es mucho más crítico que el periodístico. Aborda temáticas poco consideradas en los medios periodísticos, como el asistencialismo, el clientelismo o la corrupción en el campo de las políticas dirigidas a abatir la pobreza. También en él, es patente la tendencia a señalar que la pobreza, desatendida por los Gobiernos, suele conducir a los pobres al círculo del crimen organizado.

El discurso organizacional (entrevistas y comunicados de prensa) de funcionarios internacionales y representantes de la sociedad civil difunde datos e informes, formula recomendaciones de acción pública, encomia programas sociales y alerta sobre la situación de vulnerabilidad de algunos grupos sociales en la pobreza, como los niños o las mujeres. Este discurso tiende a ser técnico, a referirse a situaciones globales y a apelar a Gobiernos y actores sociales; en él, los pobres tampoco tienen voz propia: aparecen como pasivos y vulnerables, y pueden ser contabilizados, analizados y protegidos, pero no considerados actores.

El discurso partidista, utilizado por líderes y políticos de partidos, es fundamentalmente retórico y fluctúa entre el rechazo moral, la tentativa de denostar a los adversarios políticos y la apología de los compromisos asumidos en el combate a la pobreza. Suele cristalizar en promesas de campaña vagas e intercambiables. En este caso, la pobreza es utilizada como un botín político para obtener votos.

Por lo que corresponde al contenido de los discursos, se constata que registró algunas variaciones a lo largo del periodo bajo estudio, tanto como múltiples fueron las voces incluidas en este diario. Diversos géneros periodísticos fueron utilizados para que periodistas, expertos, funcionarios públicos nacionales e internacionales, investigadores, 
representantes de la sociedad civil y líderes partidistas pudieran hablar con mayor o menor profundidad sobre la pobreza para presentar, ensalzar y algunas veces -las menos-criticar programas sociales y acciones públicas, todo ello con el fin de dar selectivamente la voz a diversos actores y difundir datos y recomendaciones generados en distintos informes -y también promesas electorales-.

La tendencia predominante fluctuó entre una visión oficial y perspectivas moderadamente críticas. Las críticas abiertas al desempeño gubernamental en este campo fueron la excepción. ${ }^{33}$ A contrapunto de las versiones oficiales, partidistas e institucionales, sólo aparecen la denuncia de situaciones extremas y la voz de algunos académicos y expertos, que son relativamente marginales en el contexto de este diario.

En términos generales, este diario ha tendido a circunscribir el tema de la pobreza al ámbito rural y a considerar que los pobres sólo son campesinos e indígenas. Esto significa que para el diario, el nosotros incluye ideológicamente a la población urbana-predominantemente sus lectores en la Ciudad de México-, mientras el ellos se refiere a personas lejanas, sin una identidad precisa, que habitan en un mundo contrapuesto al urbano.

Ellos, los pobres, son concebidos como pasivos, vulnerables, como grupos homogéneos que pueden ser objetivados ${ }^{34}$ y utilizados políticamente, que carecen de agencia para enfrentar sus propios problemas, que no tienen voz propia y son víctimas de la violencia y el funcionamiento de la economía. Sin embargo, paradójicamente, a los pobres se les atribuye una agencia negativa, amenazadora para el nosotros en la medida en que pueden ser activados por el crimen organizado.

33. Por ello no se les dio prioridad en los análisis a profundidad que cierran este trabajo.

34. Esto contrasta con lo que ha encontrado Paugman (2007). 
En el ámbito de las agendas políticas y sociales, destacan tres tendencias: 1) situar en el centro la vinculación entre pobreza e inseguridad pública; ${ }^{35}$ 2) confinar el tema de la pobreza al medio rural e indígena; y 3) representar a los pobres como pasivos para justificar los programas orientados a esos ámbitos, permitir la manipulación política y simbólica de los pobres y utilizar a la pobreza y a los pobres como botín político que pueda servir para legitimar decisiones públicas y programas sociales o para conseguir votos en contiendas electorales.

\section{Análisis a profundidad de tres casos representativos}

Para profundizar en los hallazgos obtenidos tras el análisis general del corpus, se procede en este apartado a abordar críticamente tres casos de notas de El Universal que son representativos de las tendencias ya mencionadas. Primero, se revisa una colaboración realizada por un exfuncionario público, considerado por el diario como colaborador experto, el Dr. Ernesto Zedillo Ponce de León, quien fuera presidente de México entre 1994 y 2000 y miembro prominente del Partido Revolucionario Institucional (PRI), que estuvo en el poder federal hasta 2018.

Segundo, se analiza un reportaje crítico hecho por periodistas del diario que presenta los puntos de vista seleccionados de miembros del hogar número cuatro millones apoyado por el programa Oportunidades (la familia del Sr.

35. De hecho, la inseguridad se convirtió en una temática negativa frecuentemente empleada para dar coherencia y significatividad a las distintas visiones sobre la pobreza, y alrededor de ella se articularon distintos intereses y perspectivas sobre esta. Esta vinculación no sorprende, especialmente cuando se considera que a lo largo de los dos penúltimos sexenios (de los presidentes Vicente Fox Quesada -2000-2006- y Felipe Calderón Hinojosa -2000-20 I2-), el combate al crimen organizado fue uno de los elementos fundamentales en las agendas de los Gobiernos,y de que en el caso de Calderón incluso llevó a hablar de y a promover una guerra contra las drogas que de acuerdo con cálculos conservadores generó 60000 víctimas (CNN, 2016).

\section{6}


Jorge Copca), y que mezcla el discurso de los periodistas y una selección de las voces de actores. El reportaje se titula Quiebra el changarro de la "familia cuatro millones".

Tercero, se revisa una entrevista colectiva realizada por analistas del diario a la entonces secretaria de Desarrollo Social del Gobierno de Enrique Peña Nieto, Rosario Robles Berlanga, centrado en la nueva política frente a la pobreza. Dicha colaboración se titula Oportunidades, en fase de rediseño: Rosario Robles, y permite posicionar la mirada en las maneras de legitimar los cambios o adecuaciones de las políticas públicas frente a la pobreza.

\section{I Caso I. Un artículo de opinión escrito}

por un experto y publicado en 2002

El título del artículo-caso es Interdependencia, clave para la seguridad global. Fue publicado el 13 de marzo de 2002 en la primera plana del periódico, lo que muestra la importancia que se le confirió en el momento de su publicación. Su autor, como se dijo antes, es Ernesto Zedillo, quien para ese momento ya era expresidente y contaba con un gran reconocimiento académico internacional pues fungía -en ese entonces-como profesor visitante de la Kennedy School of Government (Harvard University).

Como contexto discursivo, el texto fue escrito en torno a la ayuda internacional para combatir la pobreza, pero la temática particular fue la justificación de la ayuda de los países ricos para combatir la pobreza en los países pobres, en un escenario de creciente inseguridad internacional.

Si cada nación pobre tiene la responsabilidad primaria de lograr su propio desarrollo, los países ricos deben ayudarlas a combatir la pobreza, no como un acto de compasión sino como parte de una estrategia para alcanzar un mundo más seguro. (Zedillo, 2002) 
El eje de dicha justificación es la vinculación entre el tema de la pobreza y el de la inseguridad pública, así como la consideración de esta última como un reto global que requiere ir "más allá de las necesarias acciones punitivas" (Zedillo, 2002). La tesis central del artículo es que la pobreza es un factor que potencia la inseguridad. En este marco, es posible responder las siguientes preguntas: ¿a quién se dirige el discurso? ¿Quiénes corresponden a la noción de nosotros? ¿Quiénes son ellos? Y ¿cuál es la estructura semántica del artículo?

La Tabla 6 muestra cómo se construyen ideológicamente las nociones nosotros y ellos en el texto del artículo.

Tabla 6. Casillero ideológico del artículo "Interdependencia, clave para la seguridad global"

Nosotros Ustedes Ellos

Nuevo nosotros

Los que combatimos la Quienes son Los pobres, que son

pobreza en los países amenazados por los una amenaza para

pobres pobres en los países unos y otros, lo que los

ricos hermana

Fuentes: elaboración propia con base en Van Dijk (2010) y Zedillo (2002).

La noción ustedes que el artículo maneja corresponde a los países ricos; la noción nosotros corresponde a quienes dentro de los países pobres combaten la pobreza, y en consecuencia no son pobres; mientras la noción ellos corresponde a los pobres, de quienes se habla en términos negativos como una amenaza para unos y otros. El discurso tiende a integrar al nosotros original y al ustedes en un nuevo nosotros, ya que ambos comparten los mismos intereses defensivos.

La Tabla 7 presenta las estructuras semánticas, y mantiene la separación entre pobres y no pobres. 


\section{Tabla 7. Estructuras semánticas del artículo}

"Interdependencia, clave para la seguridad global"

\begin{tabular}{|c|c|c|}
\hline $\begin{array}{l}\text { Estructura } \\
\text { semántica }\end{array}$ & Los pobres (ellos) & Los no pobres (nosotros) \\
\hline $\begin{array}{l}\text { Temas negativos } \\
\text { y positivos }\end{array}$ & $\begin{array}{l}\text { La pobreza y los pobres } \\
\text { amenazan a quienes no son } \\
\text { pobres en México y en los } \\
\text { países ricos. El nosotros los } \\
\text { engloba a ambos porque } \\
\text { ambos pueden ser afectados } \\
\text { por ellos }\end{array}$ & $\begin{array}{l}\text { El nosotros se refuerza } \\
\text { al señalar que cada } \\
\text { nación en desarrollo es } \\
\text { responsable de lograr su } \\
\text { propio desarrollo, y que } \\
\text { los países ricos tienen la } \\
\text { responsabilidad de ayudar } \\
\text { a aliviar la pobreza en } \\
\text { otras partes del mundo }\end{array}$ \\
\hline $\begin{array}{l}\text { Nivel de } \\
\text { descripción }\end{array}$ & $\begin{array}{l}\text { Los pobres son presentados } \\
\text { de manera muy detallada } \\
\text { como potencialmente nocivos }\end{array}$ & $\begin{array}{l}\text { Los no pobres aparecen } \\
\text { como aliados en los } \\
\text { procesos de desarrollo } \\
\text { económico y de cooperación } \\
\text { internacional }\end{array}$ \\
\hline Presuposiciones & $\begin{array}{l}\text { Se enumera una serie de } \\
\text { suposiciones negativas } \\
\text { sobre los pobres, pero no se } \\
\text { comprueban o argumentan }\end{array}$ & $\begin{array}{l}\text { - Se presupone que los no } \\
\text { pobres actúan con una } \\
\text { racionalidad moderna, con } \\
\text { arreglo a fines: desarrollo/ } \\
\text { autoprotección/alcanzar } \\
\text { un mundo más seguro } \\
\text { - Paradójicamente, se } \\
\text { reconoce que los países ricos } \\
\text { son proteccionistas y que } \\
\text { esto tiene consecuencias } \\
\text { negativas para algunos } \\
\text { seres humanos. ¿Quiénes? } \\
\text { Implícitamente los pobres }\end{array}$ \\
\hline Denominación & $\begin{array}{l}\text { Una diferencia implícita } \\
\text { entre los pobres y quienes no } \\
\text { lo son-en los países pobres } \\
\text { y los países ricos- es que los } \\
\text { primeros son potencialmente } \\
\text { dañinos para los segundos, } \\
\text { pero nada se señala en un } \\
\text { sentido inverso }\end{array}$ & $\begin{array}{l}\text { Los no pobres son } \\
\text { presentados como personas } \\
\text { modernas, racionales, con } \\
\text { formas de vida valiosas }\end{array}$ \\
\hline
\end{tabular}

Sociedad No.76 


\section{Carlos Barba Solano y Enrique Valencia Lomelí}

\begin{tabular}{|c|c|c|}
\hline $\begin{array}{l}\text { Estructura } \\
\text { semántica }\end{array}$ & Los pobres (ellos) & Los no pobres (nosotros) \\
\hline Predicación & $\begin{array}{l}\text { A los pobres se les atribuyen } \\
\text { características claramente } \\
\text { negativas, entre ellas, que } \\
\text { son ignorantes, que están } \\
\text { desesperados y enojados, } \\
\text { y que son potenciales } \\
\text { migrantes, contaminadores, } \\
\text { portadores de enfermedades } \\
\text { contagiosas, criminales, } \\
\text { fanáticos e instrumentos de } \\
\text { acciones terroristas }\end{array}$ & $\begin{array}{l}\text { Se considera que son } \\
\text { racionales y actúan } \\
\text { de manera racional y } \\
\text { estratégica, egoísta, y esto } \\
\text { es considerado positivo }\end{array}$ \\
\hline Modalidad & $\begin{array}{l}\text { La modalidad fundamental } \\
\text { en términos semánticos es } \\
\text { la posibilidad, el riesgo de } \\
\text { que los pobres se conviertan } \\
\text { en agentes nocivos para } \\
\text { nosotros y ustedes }\end{array}$ & $\begin{array}{l}\text { La modalidad fundamental } \\
\text { en términos semánticos } \\
\text { es la necesidad de que } \\
\text { quienes son racionales } \\
\text { actúen a favor de sus } \\
\text { propios intereses }\end{array}$ \\
\hline Agencia & $\begin{array}{l}\text { Se subraya el riesgo de que } \\
\text { los pobres se conviertan en } \\
\text { agentes negativos, quienes } \\
\text { por acción u omisión son } \\
\text { portadores de todos los } \\
\text { aspectos negativos ya } \\
\text { enumerados, y quienes } \\
\text { debido a su condición } \\
\text { migratoria podrían } \\
\text { transmitir, ensuciar y atacar } \\
\text { al mundo tanto en los países } \\
\text { desarrollados como en los } \\
\text { que no lo son }\end{array}$ & $\begin{array}{l}\text { Son presentados como } \\
\text { agentes que actúan a favor } \\
\text { de sus propios intereses } \\
\text { y de la colectividad de } \\
\text { no pobres; a favor del } \\
\text { desarrollo económico, } \\
\text { la autoprotección y la } \\
\text { seguridad mundial }\end{array}$ \\
\hline
\end{tabular}

Fuentes: elaboración propia con base en Van Dijk (2010) y Zedillo (2002).

El tema que da coherencia y sirve de eje interpretativo a este discurso es la amenaza que representan pretendidamente la pobreza y los pobres para el resto de la sociedad en los

\section{0}


países pobres y ricos. ${ }^{36}$ Sobre los pobres se habla mucho y mal; sobre quienes no los son se habla relativamente poco y se asume intrínsecamente que sus valores y formas de vida son buenos y racionales.

Las presuposiciones negativas sobre los pobres no están fundadas en ninguna clase de evidencia empírica ("No estoy afirmando que exista una relación directa de causa y efecto entre la pobreza y la decisión de cometer actos criminales" -Zedillo, 2002-), pero el autor deja entrever que los pobres son manipulables por los responsables intelectuales de actos criminales, quienes los utilizan como autores materiales de los mismos y como objetos susceptibles de ser fanatizados (“[...] los fanáticos que son utilizados por esos responsables intelectuales para perpetrar sus crímenes tienen menos posibilidades de estar disponibles en un mundo menos polarizado y con menos conflictos" -Zedillo, 2002-).

No se evalúa el papel de quienes no son pobres en los procesos negativos que se atribuyen a los pobres, ${ }^{37}$ pues se asume que los no pobres son básicamente racionales y actúan de manera estratégica para defender sus intereses, que en lo fundamental son buenos para todos. Se presupone que los pobres no son agentes sociales, y que cuando llegan a serlo optan por valores irracionales, destructivos e imprudentes (Tabla 7).

Por lo que corresponde a la ubicación de este texto en el ámbito de la cuestión social, se puede señalar que durante el periodo presidencial de Ernesto Zedillo se profundizaron los esfuerzos de apertura comercial de la economía mexi-

36. Hay que señalar que explícitamente el autor de la nota sitúa su discurso en el contexto del ataque terrorista a las Torres Gemelas de Nueva York, en 200I. Resulta evidente que está suponiendo que los pobres fueron un factor activo en el ataque terrorista ya mencionado, sin ofrecer ningún argumento o prueba empírica de ello. 37. Como en los procesos migratorios, en la contaminación ambiental, en la difusión de pandemias, en la organización y el ejercicio del crimen organizado, en la construcción y difusión de ideologías que generan comportamientos que pueden ser calificados como fanatismo o en la preparación y realización de acciones terroristas.

Sociedad No.76 
cana. Una de las mayores contribuciones del Gobierno de Zedillo fue la creación del Programa de Educación, Salud y Alimentación (Progresa), concebido como un programa de transferencias monetarias condicionadas, rigurosamente focalizado (Barba, 2003), y que tuvo repercusiones internacionales como modelo de acción focalizada frente a la pobreza (Valencia, 2008; Barba y Valencia, 2016).

En términos económicos, el Gobierno de Zedillo se caracterizó por ser muy riguroso en el control macroeconómico y por realizar reformas tendientes a liberalizar la economía ${ }^{38}$ y el sistema de seguridad social del sector privado (centrado en el Instituto Mexicano del Seguro Social -IMss-). ${ }^{39}$

Estos antecedentes ubican claramente al expresidente Zedillo como un convencido de los procesos de liberalización de la economía y de la focalización de la política social. Sin embargo, el texto que se acaba de analizar es muy relevante porque marca discursivamente el tránsito hacia una etapa donde la gestión de la pobreza se vinculó de manera explícita con el combate al crimen organizado, etapa que se definió durante los dos siguientes sexenios y que tuvo su apogeo durante el del presidente Felipe Calderón Hinojosa (20062012), distinguido por un agudo proceso de criminalización de la pobreza.

La visión sobre los pobres expuesta por Zedillo en su artículo de 2002 se inscribe claramente en el paradigma residual, que tiende a atribuir la pobreza a deficiencias personales de diversa índole, que respeta el funcionamiento del mercado como un elemento central de la racionalidad

38.En su periodo, se fomentaron la inversión extranjera en ferrocarriles, la administración portuaria, de carreteras y de servicios aeroportuarios, y la participación privada y extranjera en la construcción de plantas eléctricas y en el transporte, distribución y almacenamiento de gas natural; se establecieron reglas para la competencia en telecomunicaciones de larga distancia;y se profundizó la liberalización de los mercados financieros (Barba, 2003, pp. 777-784).

39. El IMss fue reformado en 1995 y pasó de ser un sistema que descansaba en un esquema de capitalización colectivo a uno de capitalización individual (Barba, 2003, p. 784).

\section{2}


moderna, que tiende a estigmatizar a los pobres y a inducir en ellos un sentimiento de culpa y fracaso, y que se basa en una desconfianza sobre la racionalidad y los valores de los pobres (Tabla 4).

5. 2 Caso 2. Un reportaje escrito por periodistas de

El Universal, con una selección de voces de participantes

del programa Oportunidades, publicado en 2003 por

Fidel Samaniego y Guillermina Guillén

El artículo Quiebra el changarro de la "familia cuatro millones" fue publicado el 19 de agosto de 2003, durante la campaña del Gobierno del entonces presidente Vicente Fox para ampliar el programa Oportunidades. ${ }^{40} \mathrm{Un}$ año antes, el presidente Fox, junto con su esposa y funcionarios de la Secretaría de Desarrollo Social, había visitado a la familia Copca, en la localidad semiurbana Huixmi (municipio de Pachuca, Hidalgo), que había obtenido el registro número cuatro millones en el padrón del programa.

Fox desayunó con esa familia e invitó a Jorge Copca y su esposa al informe presidencial del $1^{\circ}$ de septiembre de 2002, concretamente al palco de honor de la Cámara de Diputados. Prácticamente un año después, los periodistas de El Universal Fidel Samaniego y Guillermina Guillén entrevistaron a miembros de esa familia y prepararon un reportaje. La visita presidencial generó rumores en la localidad de Huixmi acerca de que los Copca habían recibido cuatro millones de pesos del presidente; como resultado de ese rumor, los Copca incluso temieron ser secuestrados. En esta nota periodística, los autores citan textualmente diversas partes de la entrevista a la familia, lo que ofrece la oportunidad de encontrar la voz de actores pobres participantes en Oportunidades (Tabla 8).

40. El programa se llamó Progresa desde su creación ya mencionada, el 8 de agosto de 1997, hasta el 6 de marzo de 2002. 
Tabla 8. Un casillero ideológico especular a partir de la nota ${ }^{41}$ "Quiebra el changarro de la 'familia cuatro millones"

\begin{tabular}{|c|c|c|}
\hline $\begin{array}{l}\text { Nosotros (nuclear) } \\
\text { Nuevo nosot }\end{array}$ & $\begin{array}{l}\text { Nosotros (extenso) } \\
\text { os }\end{array}$ & Ellos \\
\hline $\begin{array}{l}\text { Familia Copca, de la } \\
\text { localidad Huixmi (municipio } \\
\text { de Pachuca, Hidalgo), } \\
\text { participante número cuatro } \\
\text { millones en el programa } \\
\text { Oportunidades, que recibió } \\
\text { la visita del presidente } \\
\text { Vicente Fox, y que fue } \\
\text { invitada especial a la Ciudad } \\
\text { de México al informe } \\
\text { presidencial }\end{array}$ & $\begin{array}{l}\text { - Los vecinos } \\
\text { de la localidad } \\
\text { Huixmi } \\
\text { - Los pobres en } \\
\text { general }\end{array}$ & $\begin{array}{l}\text { El presidente Vicente } \\
\text { Fox, su esposa Martha } \\
\text { Sahagún, la secretaria } \\
\text { de Desarrollo Social, } \\
\text { Josefina Vázquez Mota } \\
\text { (y otros funcionarios } \\
\text { de la secretaría), y el } \\
\text { gobernador del estado }\end{array}$ \\
\hline
\end{tabular}

Fuentes: elaboración propia con base en Van Dijk (2010) y Samaniego y Guillén (2003).

Como lo muestra la Tabla 8, el nosotros de esta entrevista son los miembros de la familia Copca y algunos vecinos también entrevistados, quienes simbólicamente pueden ser incorporados en el análisis como voceros de un nosotros más amplio: los pobres. Por otra parte, el ellos, los otros incorporados a la nota, son los altos funcionarios públicos ya mencionados (Tabla 8). La nota ofrece una oportunidad notable de articular voces de estas familias pobres y acceder a su manera de elaborar la imagen de los funcionarios públicos involucrados.

La Tabla 9 presenta las estructuras semánticas contenidas en la entrevista que expresan una distancia muy grande entre los pobres que reciben (buscan y pueden recibir) y los importantes (altos funcionarios) que dan o pueden dar.

4I. El reportaje puede leerse desde diversos nosotros: los reporteros mismos de El Universal o los miembros de la familia Copca. Se optó por esta última lectura debido a la poca presencia de la voz de los actores pobres.

\section{4}


Tabla 9. Estructuras semánticas del artículo "Quiebra el changarro de la 'familia cuatro millones"

\begin{tabular}{|c|c|c|}
\hline $\begin{array}{l}\text { Estructura } \\
\text { semántica }\end{array}$ & Los pobres (nosotros) & Los no pobres (ellos) \\
\hline $\begin{array}{l}\text { Temas negativos } \\
\text { y positivos }\end{array}$ & $\begin{array}{l}\text { - Los principales entrevistados } \\
\text { se autoidentifican como } \\
\text { pobres, que dicen de sí mismos } \\
\text { estar "rozándonos con los } \\
\text { importantes" } \\
\text { - Aparecen otros pobres, } \\
\text { mujeres de la localidad } \\
\text { de Huixmi, como quienes } \\
\text { "mintieron cuando se levantó } \\
\text { el padrón [de Oportunidades] } \\
\text { [...]. Dijeron que no tenían } \\
\text { refrigerador, ni lavadora [...]" }\end{array}$ & $\begin{array}{l}\text { El adjetivo importantes, } \\
\text { adjudicado por los } \\
\text { entrevistados a los } \\
\text { altos funcionarios que } \\
\text { los visitaron, tiene } \\
\text { un sentido crítico de } \\
\text { distancia: son quienes no } \\
\text { contestan las llamadas } \\
\text { telefónicas ni reciben a } \\
\text { los pobres }\end{array}$ \\
\hline $\begin{array}{l}\text { Nivel de } \\
\text { descripción }\end{array}$ & $\begin{array}{l}\text { - Los pobres son presentados } \\
\text { como buscadores de ayuda y } \\
\text { como objeto de promesas y de } \\
\text { regalos } \\
\text { - Se genera el rumor de que los } \\
\text { miembros de la familia Copca } \\
\text { reciben cuatro millones de } \\
\text { pesos del presidente }\end{array}$ & $\begin{array}{l}\text { - El presidente es } \\
\text { presentado como quien } \\
\text { ofrece amistad a los } \\
\text { pobres, que utiliza } \\
\text { gentileza y deferencia y } \\
\text { usa frases como "en Los } \\
\text { Pinos está tu casa" } \\
\text { - Los altos funcionarios, } \\
\text { a quienes solicitan ayuda } \\
\text { los pobres, son descritos } \\
\text { como prometedores que } \\
\text { cumplen parcialmente, } \\
\text { que frente al presidente } \\
\text { "se portan de una } \\
\text { manera y luego ya ni } \\
\text { hacen caso" }\end{array}$ \\
\hline
\end{tabular}




\section{Carlos Barba Solano y Enrique Valencia Lomelí}

\begin{tabular}{|c|c|c|}
\hline $\begin{array}{l}\text { Estructura } \\
\text { semántica }\end{array}$ & Los pobres (nosotros) & Los no pobres (ellos) \\
\hline Presuposiciones & $\begin{array}{l}\text { - Los pobres entrevistados } \\
\text { buscan a los funcionarios } \\
\text { públicos para recibir apoyos, } \\
\text { pero dudan de la eficiencia de } \\
\text { los mismos } \\
\text { - Los pobres entrevistados } \\
\text { plantean una diferencia entre } \\
\text { la actitud del presidente (“dijo } \\
\text { que es mi amigo") y la de los } \\
\text { otros funcionarios, que no } \\
\text { cumplen. En este sentido, se } \\
\text { salva la figura presidencial } \\
\text { - Se refleja la idea de que } \\
\text { algunos pobres mienten para } \\
\text { poder ingresar al programa } \\
\text { Oportunidades, lo que genera } \\
\text { una sospecha moral sobre la } \\
\text { conducta de todos los pobres }\end{array}$ & $\begin{array}{l}\text { De acuerdo con los } \\
\text { entrevistados (y con los } \\
\text { entrevistadores), los } \\
\text { funcionarios aparecen } \\
\text { como quienes suponen } \\
\text { que los apoyos son para } \\
\text { que los pobres dejen de } \\
\text { serlo }\end{array}$ \\
\hline Denominación & $\begin{array}{l}\text { Los pobres reciben en su } \\
\text { casa a los altos funcionarios } \\
\text { y les invitan el desayuno } \\
\text { con platillos populares ("la } \\
\text { barbacoa, la pancita y el } \\
\text { consomé") }\end{array}$ & $\begin{array}{l}\text { La familia Copca } \\
\text { presenta a los altos } \\
\text { funcionarios visitantes } \\
\text { como sus invitantes a un } \\
\text { espectáculo en el informe } \\
\text { presidencial: "la señora } \\
\text { Marta risa y risa con } \\
\text { nosotros, y don Vicente } \\
\text { que nos saluda desde } \\
\text { allá arriba" }\end{array}$ \\
\hline
\end{tabular}

\section{6}




\begin{tabular}{|c|c|c|}
\hline $\begin{array}{l}\text { Estructura } \\
\text { semántica }\end{array}$ & Los pobres (nosotros) & Los no pobres (ellos) \\
\hline Predicación & $\begin{array}{l}\text { - Las características que los } \\
\text { pobres se autoatribuyen se } \\
\text { ligan a sus tribulaciones } \\
\text { económicas: se mencionan } \\
\text { preocupaciones por las } \\
\text { condiciones de un microcrédito } \\
\text { recibido (20 000.00 pesos), } \\
\text { necesidad de deshacerse de } \\
\text { activos (venta de dos vacas) } \\
\text { y pérdida de beneficios de } \\
\text { Oportunidades (suspensión por } \\
\text { reprobación) } \\
\text { - También se atribuyen } \\
\text { características claramente } \\
\text { negativas a los pobres: algunas } \\
\text { mujeres mentirosas, vecinos } \\
\text { envidiosos de la familia Copca }\end{array}$ & $\begin{array}{l}\text { La principal } \\
\text { característica de los altos } \\
\text { funcionarios, implícita } \\
\text { en el reportaje, es que } \\
\text { crean un espectáculo } \\
\text { con la familia cuatro } \\
\text { millones y después } \\
\text { prácticamente la } \\
\text { abandonan }\end{array}$ \\
\hline Modalidad & $\begin{array}{l}\text { La modalidad fundamental en } \\
\text { términos semánticos es la de } \\
\text { demandantes de apoyos para } \\
\text { intentar salir de la pobreza }\end{array}$ & $\begin{array}{l}\text { La modalidad } \\
\text { fundamental en términos } \\
\text { semánticos es la débil } \\
\text { probabilidad de que los } \\
\text { funcionarios cumplan } \\
\text { sus promesas. Cuando } \\
\text { las cumplen, lo hacen de } \\
\text { manera incompleta (sólo } \\
\text { la concesión de un taxi, } \\
\text { pero sin crédito para } \\
\text { obtener un automóvil, } \\
\text { y un microcrédito para } \\
\text { una fracasada tienda o } \\
\text { changarro) }\end{array}$ \\
\hline
\end{tabular}


Estructura

semántica

Agencia
Los pobres (nosotros)

La agencia de los pobres se

centra en solicitar (ayuda, apoyos), en generar actividades económicas (tienda y servicio de taxi) y en algunos casos en maniobrar (dar información falsa) para incorporarse a Oportunidades
Los no pobres (ellos)

La agencia de los funcionarios se centra en prometer generar apoyos a los pobres y acercarse a la familia cuatro millones del programa Oportunidades

Fuentes: elaboración propia con base en Van Dijk (2010) y Samaniego y Guillén (2003).

Respecto a la ubicación de este texto en el ámbito de la cuestión social, se aprecia que los entrevistadores ofrecen la posibilidad de hacer oír la voz de pobres incorporados a Oportunidades, como un ejemplo de información emergente. Paradójicamente, los pobres entrevistados, aunque críticos del escenario o espectáculo creado por el Gobierno de Fox para celebrar la cobertura del programa hasta cuatro millones, interiorizan el paradigma de la focalización como buscadores legítimos de apoyo (implícitamente como merecedores del mismo), lo que revela claramente el ejercicio de violencia simbólica que ese programa ejerce sobre ellos (Tabla 4).

Ni los entrevistadores, con sus preguntas (implícitas en el texto), ni los entrevistados pobres articulan en ningún momento en la nota la visión de derecho social a un nivel de vida aceptable. La agencia que más se destaca en el texto, de diversas maneras, es la de los pobres buscadores de ayuda, de apoyos, y no de exigentes de un derecho. Incluso, esta agencia puede llevar a algunos pobres a mentir y a buscar ilegítimamente la incorporación a un subsidio gubernamental, por lo que nuevamente en este último caso los pobres son estigmatizados.

\section{8}


Más allá de la pretensión oficial de que Oportunidades realiza una focalización eficiente y ajena a la posibilidad de la utilización política, la entrevista revela que la práctica gubernamental manipula a los beneficiarios de este programa y los usa como parte de un espectáculo político centrado en la figura presidencial. Los entrevistados, por una parte, se plantean como felices en el escenario creado y, por otra, cuestionan los resultados del mismo: en el espectáculo juegan un papel relevante las promesas y el supuesto acercamiento/amistad entre pobres e importantes (funcionarios), pero con el transcurso del año los entrevistados caen en la cuenta de que el escenario cambió: recibieron promesas, tarjetas de presentación, fotos e invitaciones a eventos públicos, pero ellos continúan con sus tribulaciones económicas.

El ámbito de la vida cotidiana (necesidades y preocupaciones de la pobreza) es diferente al escenario político. Sin embargo, a pesar de la crítica, la figura presidencial puede salvarse relativamente y el paradigma del pobre necesitado de apoyo no es cuestionado, e incluso es fortalecido simbólicamente en la misma crítica de la familia Copca.

\section{3 Caso 3. Una entrevista colectiva de analistas} de El Universal a la secretaria de Desarrollo Social, publicada en 2013

La entrevista titulada Oportunidades, en fase de rediseño: Rosario Robles fue publicada el 25 de marzo de 2013, a menos de cuatro meses del inicio del periodo de gobierno del presidente Enrique Peña Nieto, en un contexto marcado por la revaloración de los programas sociales ya existentes y por el incremento de la pobreza. ${ }^{42}$

La cobertura de Oportunidades creció en los Gobiernos de Vicente Fox y de Felipe Calderón, hasta superar cinco

42. De acuerdo con el informe del Consejo Nacional de Evaluación de la Política de Desarrollo Social (CONEVAL) (Valencia, Foust, y Tetreault, 20I2b). 
millones de hogares a fines de 2012. Por ello, aunque este programa no fue diseñado para reducir la pobreza en el corto plazo, las autoridades esperaban una reducción importante, e incluso durante el sexenio de Fox se manejó públicamente la idea de que había contribuido significativamente a la reducción de la problemática. Sin embargo, de manera oficial, durante el Gobierno de Calderón la pobreza repuntó.

Por ello, en 2013 el Gobierno entrante discutía qué hacer con Oportunidades. En ese momento, Rosario Robles, quien era la secretaria de Desarrollo Social, fue invitada por $E l$ Universal para entrevistarse con ocho colaboradores (articulistas), consultores y académicos de diversas instituciones.

La periodista Mariana León Medina construyó una nota con los principales resultados de la entrevista colectiva, en la que incluyó párrafos textuales (entrecomillados) de las respuestas de Robles. La nota permite analizar algunos elementos de la visión de los hacedores de la política pública frente a la pobreza y del lugar que otorgan a los pobres en un esquema de reforma.

Tabla 10. Casillero ideológico de la entrevista ${ }^{43}$ "Oportunidades, en fase de rediseño: Rosario Robles"

Nosotros (nuclear) Nosotros (extenso)

Nuevo nosotros

(Gobierno) Quienes Con quienes se

pensamos, reflexionamos, está rediseñando

rediseñamos las acciones el programa

frente a la pobreza

Oportunidades

\section{Ellos}

La gente, los pobres que continúan (o pretenden continuar) en el programa Oportunidades

Fuentes: elaboración propia con base en Van Dijk (2010) y León (2013).

43. La entrevista colectiva incluye diversos tópicos, aunque la mayor parte del texto se centra en las acciones frente a la pobreza. Podrían elaborarse otros cuadros de casillero ideológico, pero sólo se trabaja el considerado más relevante y destacado por quien firma la nota periodística.

\section{0}


La Tabla 10 muestra que en esta nota el nosotros corresponde al Gobierno de Peña Nieto como evaluador del programa Oportunidades y de su futuro, en conjunción con instituciones financieras internacionales (como el BID y el BM) y académicos de la UNAM. Los pobres son ellos, a quienes se imputa desear mantenerse permanentemente en el programa.

La entrevista aporta la posibilidad de analizar cómo se construye la política pública frente a la pobreza, cómo se evalúa y con quiénes plantea aliarse el Gobierno para rediseñarla, y también muestra el ausente rol de los pobres en este proceso. Puede incluso señalarse que estos aparecen como un obstáculo para una reingeniería más adecuada y eficiente del programa.

La Tabla 11 presenta las estructuras semánticas contenidas en la entrevista colectiva, que expresan una distancia entre los funcionarios del Gobierno y los pobres dependientes, quienes hipotéticamente requieren incentivos para dejar los subsidios y salir del padrón del programa.

Tabla 11. Estructuras semánticas de la nota "Oportunidades, en fase de rediseño: Rosario Robles"

\begin{tabular}{|c|c|c|}
\hline $\begin{array}{l}\text { Estructura } \\
\text { semántica }\end{array}$ & Los pobres (ellos) & Los no pobres (nosotros) \\
\hline Temas negativos & Familias pobres que & El Gobierno de Peña \\
\hline y positivos & "viven eternamente en & Nieto, que aparece como \\
\hline & Oportunidades", sin & capaz de identificar \\
\hline & incentivos adecuados para & salidas a la pobreza (tema \\
\hline & salir del programa y dejar & positivo) y de revertir los \\
\hline & de recibir subsidios & límites de las anteriores \\
\hline & & administraciones \\
\hline & & que apostaron a las \\
\hline & & $\begin{array}{l}\text { transferencias monetarias } \\
\text { (tema negativo) }\end{array}$ \\
\hline
\end{tabular}

Sociedad 8 No.76 


\section{Carlos Barba Solano y Enrique Valencia Lomelí}

Estructura

semántica

Nivel de

descripción

Presuposiciones

Denominación
Los pobres (ellos)

Los no pobres (nosotros)

Los pobres son presentados

como dependientes

de subsidios, apoyos,

transferencias monetarias, programas, y también

como posibles votantes en

caso de satisfacción por los

resultados de las políticas

gubernamentales

Se supone que la inclusión

productiva, los proyectos

productivos y el ingreso

proveniente del trabajo

son el camino adecuado

("la única posibilidad")

para dejar la pobreza. No

se plantean los problemas

estructurales asociados

al ingreso (insuficiente)

de los pobres, ni se

problematiza (más allá de

la inclinación de los pobres

a la dependencia) por qué

algunas familias siguen

durante quince años en el

padrón de Oportunidades

Se subraya la diferencia

entre los pobres

dependientes (malos) y

los que dejan la pobreza,

salen de los programas

gubernamentales y

encuentran trabajo o

actividades productivas

(buenos)
El Gobierno reflexiona, rediseña, dialoga con instituciones, realiza esfuerzos de articulación, tiene capacidad bastante limitada para manipular electoralmente los programas, instruye para no condicionarlos, puede solucionar la pobreza El conjunto capaz de reflexionar y rediseñar las acciones frente a la pobreza está integrado por el Gobierno, instituciones financieras (BID y BM) y académicos (UNAM) (nosotros extenso). En el nosotros nuclear, la fuerza está en la Secretaría de Hacienda "porque en su mano está el tema de la pobreza". La sociedad acompaña el replanteamiento que hace el Gobierno

Diferencia entre Gobiernos creyentes monetarias, no eficientes (se menciona el aumento en el número de mexicanos en marginación), y el Gobierno con enfoque productivo, centrado en la generación de ingresos productivos y del trabajo en las transferencias 


\begin{tabular}{|c|c|c|}
\hline $\begin{array}{l}\text { Estructura } \\
\text { semántica }\end{array}$ & Los pobres (ellos) & Los no pobres (nosotros) \\
\hline Predicación & $\begin{array}{l}\text { A los pobres dependientes se } \\
\text { les atribuyen características } \\
\text { claramente negativas; y } \\
\text { a los pobres que obtienen } \\
\text { trabajo, características } \\
\text { positivas: el trabajo "en } \\
\text { términos de autonomía y } \\
\text { de dignidad es lo mejor". } \\
\text { Implícitamente, recibir } \\
\text { transferencias no es un buen } \\
\text { camino para la autonomía y } \\
\text { dignidad }\end{array}$ & $\begin{array}{l}\text { Las características } \\
\text { atribuidas al Gobierno } \\
\text { son en su mayor parte } \\
\text { positivas (reflexivo, } \\
\text { articulador, dialogador, no } \\
\text { condicionante, con poder } \\
\text { de resolver la pobreza); } \\
\text { también se le adjudican } \\
\text { atributos negativos (la } \\
\text { inercia burocrática y las } \\
\text { equivocaciones de otras } \\
\text { administraciones) }\end{array}$ \\
\hline Modalidad & $\begin{array}{l}\text { La posibilidad, el riesgo, es } \\
\text { que los pobres se conviertan } \\
\text { en dependientes del } \\
\text { Gobierno y que no trabajen }\end{array}$ & $\begin{array}{l}\text { Por una parte, se } \\
\text { menciona la necesidad } \\
\text { de rediseñar las acciones } \\
\text { frente a la pobreza } \\
\text { (para romper con la } \\
\text { dependencia); por otra, } \\
\text { la probabilidad de que } \\
\text { la economía crezca y la } \\
\text { distribución del ingreso } \\
\text { sea más equitativa }\end{array}$ \\
\hline Agencia & $\begin{array}{l}\text { Además del riesgo de que } \\
\text { los pobres se conviertan } \\
\text { en agentes negativos } \\
\text { (dependientes sin trabajo), } \\
\text { se les convierte en meros } \\
\text { objetos cuando se pretende } \\
\text { rediseñar los programas. } \\
\text { La agencia positiva de los } \\
\text { pobres se circunscribe a que } \\
\text { trabajen para graduarse } \\
\text { y dejar el padrón de } \\
\text { Oportunidades }\end{array}$ & $\begin{array}{l}\text { Se afirma que el Gobierno } \\
\text { actual realiza un "esfuerzo } \\
\text { titánico" para "alinear } \\
\text { los esfuerzos" y trabajar. } \\
\text { La agencia principal se le } \\
\text { confiere al secretario de } \\
\text { Hacienda, aunque también } \\
\text { se subraya la agencia } \\
\text { rediseñadora de la propia } \\
\text { Secretaría de Desarrollo } \\
\text { Social }\end{array}$ \\
\hline
\end{tabular}

Fuentes: elaboración propia con base en Van Dijk (2010) y León (2013).

Situados en el ámbito de la cuestión social, la Tabla 11 permite observar que la entrevista analizada reafirma el pre- 
dominio del paradigma de la focalización en la perspectiva gubernamental sobre las políticas sociales. La entrevistada se propone como reformadora de las acciones públicas, pero lo hace con elementos clave del paradigma de la focalización: subraya que los pobres deben ser objeto de apoyos sólo temporales, fundamentalmente productivos, y considera que la distorsión de los subsidios se debe a los pobres mismos y a incentivos erróneos: los incentivos han funcionado para que los empadronados no salgan del programa, y hay familias que viven eternamente en Oportunidades.

Por otra parte, cuando se subraya que es mejor que el ingreso provenga del trabajo de la gente, y que por ello se requiere apoyar la inclusión productiva, implícitamente se señala la falta de trabajo entre los pobres como una deficiencia de estos, mientras que no se cuestiona la insuficiencia de los ingresos obtenidos por los pobres, ni el predominio de empleos precarios e informales, con bajos salarios. Por ello, se les estigmatiza y se considera a los beneficiarios como una carga y un obstáculo para el rediseño de la política pública.

Otro elemento focalizador es el fortalecimiento del diseño y puesta en práctica de aspectos tecnocráticos de los programas sociales, entre otras cuestiones debido a la utilización de pruebas de medios rigurosas (Tabla 4). La entrevista muestra este enfoque tecnocrático: el rediseño de los programas excluye rotundamente la participación de los beneficiarios del programa. El potencial para enfrentar la pobreza se adjudica en parte a la Secretaría de Hacienda (sin especificar por qué), y se hace depender de un cambio de conducta de los pobres, que son narrados como pretendidamente renuentes a trabajar o ser incluidos productivamente. La agencia de los pobres incorporada en este esquema no está en su participación o exigibilidad de derechos, sino en su disposición a trabajar para salir pronto del programa, para graduarse de él. 
La construcción social de la pobreza y la desvalorización de los pobres en México en quince años del diario El Universal

\section{Hallazgos y conclusiones}

En general, se encuentra que el abordaje de la pobreza en el diario El Universal tiende de manera predominante a subrayar la perspectiva oficial gubernamental, aunque ocasionalmente se incluyen algunas visiones moderadamente críticas (especialmente de los articulistas). El tema de la pobreza se circunscribe al ámbito rural: los pobres tienden a ser presentados como campesinos e indígenas, y hay muy poca presencia de la pobreza urbana.

Por otra parte, habitualmente no se les reconoce agencia a los campesinos e indígenas pobres para resolver su propia situación; se les presenta como carentes de voz propia, como meros objetos sociales, pasivos, manipulables, víctimas y vulnerables, y cuando se les concibe como actores significativos en la vida social, se les confiere una agencia negativa vinculada con actividades criminales. En este sentido, los pobres son vistos como amenazantes para la seguridad pública.

En términos particulares, en los tres casos seleccionados para el análisis, los resultados del ACD sobre la pobreza en el diario El Universal son los siguientes:

- Los pobres son presentados como una amenaza para la seguridad de los no pobres; son exhibidos como portadores de características negativas (ignorantes, mentirosos, desesperados, criminales, potenciales migrantes peligrosos) y como una carga para la sociedad, pues se describen como dependientes de los programas gubernamentales, sospechosos de intentar vivir de los subsidios públicos y no de su propio trabajo y responsabilidad personal.

- Los pobres no son vistos como derechohabientes ni como capaces de participar en el diseño de las acciones públicas, aunque excepcionalmente son concebidos como capaces de criticar la manipulación de que son objeto a través de espectáculos políticos y mediáticos. Sin embargo, dicha crítica se presenta como restringida al 
incumplimiento de la promesas formuladas por algunas autoridades.

- En contraste, los no pobres son caracterizados como seres racionales y modernos, capaces de autoprotegerse, mientras el Gobierno (y sus aliados) son mostrados como competentes para reflexionar, dialogar y rediseñar los programas de acción frente a la pobreza.

Todos estos hallazgos indican que en el diario El Universal predomina una visión sobre la pobreza que refuerza una construcción negativa sobre los pobres, que a su vez se articula con y refuerza el enfoque focalizado y neoliberal de las políticas sociales de los últimos treinta años. Esta mirada negativa coincide con antiguas tradiciones históricas que vinculan en tensión, por una parte, el desprecio y la sospecha hacia los pobres y, por otra, compasión y búsqueda de soluciones para remediar su situación (Paugman, Cousin, Giorgetti, y Naudet, 2017, pp. 275-276).

Después de este análisis, resulta evidente que la violencia simbólica ejercida en contra de los pobres utiliza los discursos no sólo institucionales, sino también periodísticos. La eficacia de estos mecanismos se hace patente en el análisis del caso de la familia Copca de la localidad semiurbana Huixmi, que tal como lo sugiere Bourdieu interioriza y acepta la violencia simbólica reproducida a través de las políticas sociales del Estado mexicano.

Finalmente, este trabajo hace patente la necesidad de reforzar la investigación sobre los discursos sobre la pobreza que circulan en los medios impresos, y seguramente en otros medios como la televisión, la radio y la televisión, porque en ellos se libra una lucha simbólica muy importante, que tiene repercusiones en las representaciones sociales sobre la pobreza que a su vez, como se ha visto, con frecuencia contribuyen a la reproducción de visiones negativas y estigmatizadoras acerca de la pobreza y de los pobres. 
Barba, C. (2003). El nuevo paradigma de bienestar social residual Bibliografía y deslocalizado. Reformas de los regímenes de bienestar en la OCDE, América Latina y México [tesis doctoral inédita]. Universidad de Guadalajara y Centro de Investigación y Estudios Superiores en Antropología Social: Guadalajara. Barba, C. (2007a). ¿Reducir la pobreza o construir ciudadanía social para todos? América Latina: regímenes de bienestar en transición al iniciar el siglo XXI. Guadalajara: Universidad de Guadalajara.

Barba, C. (2007b). Nuevos actores internacionales y nuevos paradigmas de bienestar en América Latina. En C. Barba (Aut.), ¿Reducir la pobreza o construir ciudadanía social para todos? América Latina: regímenes de bienestar en transición al iniciar el siglo XXI (Pp. 197-249). Guadalajara: Universidad de Guadalajara.

Barba, C. (2010). La nueva cuestión social en el mundo y en América Latina: más allá de la pobreza. Renglones, (62), 24-44. Recuperado de https://rei.iteso.mx/ handle/ I I I I7/230

Barba, C. (20/2). La construcción visual de la pobreza en el régimen discursivo de los programas sociales en México. En S. Corona (Coord.), Pura imagen (pp. 2 I -47). México: Consejo Nacional para la Cultura y las Artes.

Barba, C. (20I3). Universalismo y focalización. En A. Ivo (Coord.), Dicionário 'Desenvolvimento e Questão Social' (pp. 528-533). Bahía, Brasil: Universidad Federal de Bahía. Barba, C., y Silva,Y.(20 I8). El ADN de los informes internacionales sobre desigualdad realizados por la OCDE, la CEPAL y OXFAM durante la segunda década del siglo XXI. En C. Midaglia, G. Ordoñez, y E. Valencia (Coords.), Políticas sociales en América Latina en los inicios del siglo XXI. Innovaciones, inercias y retrocesos (pp. 27 I-298). Buenos Aires: CLACSO y El Colegio de la Frontera Norte.

Barba, C., y Valencia, E. (20I4). Brasil y México: regímenes duales en transición divergente [ponencia presentada 
Bibliografía 
Bourdieu, P. (1997). Razones prácticas. Sobre la teoría de la Bibliografía acción. Barcelona:Anagrama.

Bourdieu, P. (200 I). Poder, derecho y clase social. Bilbao: Editorial Desclée de Brouwer.

Bourdieu, P. (2003). El oficio de científico. Ciencia de la ciencia y reflexividad. Curso del Collège de France 2000-200I. Barcelona:Anagrama.

Bourdieu, P., yWacquant, L. (2005). Lenguaje, género y violencia simbólica. En P. Bourdieu, y L. Wacquant (Auts.), Una invitación a la sociología reflexiva (Pp. 205-248). Buenos Aires: Siglo XXI Editores.

CNN (20I6). La guerra de México contra las drogas en datos. Recuperado de https://cnnespanol.cnn.com/2016/01/08/ la-guerra-de-mexico-contra-las-drogas-en-datos/

Consejo Nacional de Evaluación de la Política de Desarrollo Social (2016). Resultados de pobreza en México 2016 a nivel nacional y por entidades federativas. Recuperado de https://www.coneval.org.mx/Medicion/Paginas/Pobrezalnicio.aspx

Esping-Andersen, G. (1990). The Three Worlds of Welfare Capitalism. Cambridge: Polity Press.

Esping-Andersen, G., y Corpi, W. (1993). El modelo escandinavo: del alivio a la pobreza a los sistemas avanzados de protección. En B. Klinsberg (Ed.), Pobreza, un tema impostergable (pp. 369-420). México: Fondo de Cultura Económica, PNUD, CLAD.

Filgueira, F. (20I3). Hacia un modelo de protección social universal en América Latina. Santiago de Chile: CEPAL.

Geertz, C. (2003). La interpretación de las culturas. Barcelona: Gedisa.

Gramsci,A. (198I). Cuadernos de la cárcel. México: Era.

Gutiérrez Cham, G. (2003). Teoría del discurso. Estrategias periodísticas. Guadalajara: Universidad de Guadalajara. 
Bibliografía $\mid$ Gutiérrez Vidrio, S. (2010). Discurso periodístico: una propuesta analítica. Comunicación y sociedad, (14), 169-198. doi https://doi.org/I0.32870/cys.v0i I 4.I285

Hall, S. (2004). Codificación y descodificación en el discurso televisivo. Cuadernos de información y comunicación, (9), 215-236. Recuperado de https://revistas.ucm.es/index. $\mathrm{php} / \mathrm{ClYC} /$ article/view/8I62

Ivo, A. (2008). Georg Simmel e a 'sociologia da pobreza'. Caderno CRH, 25(52), I7I-I8I.

Lausberg, H. (1993). Elementos de la retórica literaria. Madrid: Gredos.

León, M. (25 de marzo de 20I3). Oportunidades, en fase de rediseño: Rosario Robles. El Universal. Recuperado de https://archivo.eluniversal.com.mx/notas/912508.html Lukes, S. (1976). Power. Londres: MacMillan Press.

Marshall,T.(2007). Ciudadanía y clase social. Barcelona: Alianza Editorial.

Mkandawire,T. (2005). Targeting and Universalism in Poverty Reduction. Social Policy and Development Programme, (23). Recuperado de http://citeseerx.ist.psu.edu/viewdoc/ download?doi= I0.1.1.579.9254\&rep=rep I \&type=pdf

Molina, C. (Ed.) (2006). Universalismo básico. Una nueva política social para América Latina. Washington: Banco Interamericano de Desarrollo, Planeta.

Ocampo, J.A. (2008). Las concepciones de la política social: universalismo vs. focalización. Nueva sociedad, (2I3), 36-6I. Recuperado de https://nuso.org/media/articles/ downloads/352I_I.pdf

Ordoñez, G. (2002). La política social y el combate a la pobreza en México. México: UnAM.

Paugman, S. (2007). Las formas elementales de la pobreza. Madrid:Alianza Editorial.

Paugman, S., Cousin, B., Giorgetti, C., y Naudet, J. (20I7). Ce que les riches pensent des pauvres. París:Éditions du Seuil.

\section{0}


Sáez, N. (2003). Análisis lingüístico del discurso argumentativo subyacente en algunos spots publicitarios que influyen en nuestra ideología social. Cyber humanitatis, 27(invierno). Recuperado de http://web.uchile.cl/vignette/cyberhumanitatis-aaa/CDA/texto_simple2/0, I 255,SCID\%253D75 I 4\%2526ISID\%253D347,00.html

Samaniego, F., y Guillén, G. ( 19 de agosto de 2003). Quiebra changarro de la "familia cuatro millones". El Universal. Recuperado de https://archivo.eluniversal.com.mx/ primera/ / 4982.html

Saraví, G. (2008). Mundos aislados: segregación urbana y desigualdad en la Ciudad de México. Eure, $x x \operatorname{xiv}(103)$, 93-I I0. Recuperado de http://www.iiac.cnrs.fr/MG/pdf/ SARAVI_Mundosaislados.pdf

Saraví, G. (20I5). Juventudes fragmentadas: socialización, clase y cultura en la construcción de la desigualdad. México: FLACSO México y CIESAS.

Simmel, G. ( 1977$)$. El pobre. En G. Simmel (Aut.), Sociología. Estudios sobre las formas de socialización (pp. 467-499). México: Fondo de Cultura Económica.

Skocpol, T. (1995). Social Policy in the United States. Future Possibilities in Historical Perspective. Princeton: Princeton University Press.

Tilly, C. (2000). La desigualdad persistente. Buenos Aires: Manantial.

Titmuss, R. (2007). Universalism versus Selection. En M. Titmuss, y A. Seldon (Auts.), Commitment to Welfare (pp. 128-137). Londres:Allen and Unwin.

Valencia, E. (1989). Metodología del análisis de coyuntura [tesis de maestría inédita]. Universidad Iberoamericana: México.

Valencia, E. (2008). Las transferencias monetarias condicionadas como política social en América Latina. Un balance: aportes, límites y debates. Annual review of sociology, 
Bibliografía 